\title{
ANTIGUOS PROBLEMAS Y NUEVOS MÉTODOS PARA EL ESTUDIO DE LAS CRISIS EN LA ASTURIAS RURAL DE LA MODERNIDAD*
}

\author{
María del Carmen ANSÓn CALvo \\ Universidad do Oviedo
}

\begin{abstract}
Resumen
Asturias en el siglo XVIII sufrió diversas crisis de mortalidad, algunas de ellas casi desconocidas hasta ahora, a pesar de su fuerte intensidad. Este trabajo, que utiliza fundamentalmente fuentes objetivas, presenta la novedad de intentar «detectar» estas crisis en base, no sólo de los datos obtenidos de las actas sacramentales de entierros, sino también, en gran medida, de los procedentes de las actas sacramentales de bautismos. Tratados los datos con métodos y medios informáticos $\mathrm{y}$, analizándolos estadísticamente, los resultados obtenidos nos permiten presentar una panorámica bastante completa de las crisis de mortalidad y de sus posibles causas, así como de las consecuencias sufridas por la población rural asturiana a lo largo de la XVII centuria.
\end{abstract}

\begin{abstract}
In this paper we try to show the tentative results of an analysis of the temporal evolution, along de XVIII century, of the baptism and burial parochial data of a, we think, large number of population entities of the rural Asturias in order to determine the mortality crisis which they supported. We have tested the statistical way as the different data represent the collective and we have deduced that the baptism data permit, with less effort, obtain quantitative conclusions about the effects on population of the detected crisis. Comparing the dates of appearance of the crisis with those coming from XVIII century historic literature, we have obtained supports to our methods of work. We pretend to analyse other collectives in order to test more the general applicability of the method.
\end{abstract}

\footnotetext{
* Una parte importante de este trabajo se presentó en el VII Congreso de la Asociación de Demografia Histórica (ADEH). Granada, mayo, 2004.
} 
En un trabajo publicado en el año 1986, Pérez Moreda y Reher' llevan cabo un intento de racionalizar las «oscilaciones a largo plazo de la población europea» entre los años 1200 a 1850 «mediante mecanismos demográficos», es decir, mediante hipótesis basadas en la actuación conjunta de la mortalidad, nupcialidad y fecundidad como motores de dichos mecanismos. En ese trabajo, además de utilizar como identificación clasificatoria la de «regímenes de alta y baja presión», que reside en las prácticas nupciales según los modelos de Hajnal, los autores adscriben España, para explicar su crecimiento demográfico anterior al siglo XVII, a un modelo de «nupcialidad intensa, estimulada por unas densidades demográficas relativamente bajas $\rangle^{2}$. Consideran además que durante la primera mitad del siglo XVII, que fue muy negativa para España, «el crecimiento castellano parece atenuarse desde la década de 1570, debido a los efectos de una nupcialidad cada vez más restringida» ${ }^{3}$ pues, «una elevación de la edad media en las primeras nupcias femeninas, de 1,5 años aproximadamente, entre la segunda mitad del siglo XVI y la primera del XVII, como es la que se desprende de los escasos datos hasta ahora disponibles, habrían afectado notablemente a las tasas de crecimiento, sobre todo si se vio acompañada de un aumento paralelo del celibato definitivo». Sobre este último extremo también he contribuido con una aportación ${ }^{4}$. Además, siguen Pérez Moreda y Reher, «estos sombríos presagios de un estancamiento de la población dieron paso al desastre demográfico ocasionado por las grandes epidemias de peste de 1596-1602». Sin embargo, «hacia 1700 un profundo cambio empezó a afectar a toda Europa. A partir de entonces la frecuencia y gravedad de las crisis de mortalidad fueron descendiendo gradualmente en todos los sitios», «muchas enfermedades epidémicas siguieron afectando todavía a toda Europa, pero su incidencia global en las tasas de crecimiento había empezado a descender rápidamente» ${ }^{5}$.

Pérez Moreda y Reher indican que «la influencia de la mortalidad sobre las tasas de crecimiento es, por lo común, mucho mayor en un sistema de alta presión que en otro de baja presión» mientras que «la nupcialidad y, en consecuencia, la fecundidad tienen escasas posibilidades de actuar generando un decisivo aumento de las tasas de crecimiento a largo plazo» ${ }^{6}$. En este sentido parece que el acopio de datos lo más fidedignos posible sobre la mortalidad en una región como Asturias es suficientemente interesante, tanto por si mismos, como por el papel de Asturias como representante relevante de la España más fecunda en el año 1787, ya que sólo cuatro regiones (Jaén, Cataluña, Guipúzcoa y Canarias) que, como tales, se recogen en las hojas del Censo

1. PÉREZ MOREDA, V. y ReHER, D. S. «Mecanismos demográficos y oscilaciones a largo plazo de la población europea (1200-1850)» Revista de Historia Económica. Año IV, 3, Madrid,1986, pp. 467-490.

2. Ibid.; p. 472.

3. Ibid.; p. 473.

4. ANsón CALVO, M. C. «Búsqueda de criterios para establecer el carácter ciudadano de las poblaciones del Reino de Aragón durante el Antiguo Régimen». Actas del XVII Congreso de Historia de la Corona de Aragón, V. I, Barcelona 2003, pp. 145-170.

5. Pérez Moreda, V. y Reher, D. S. O. cit., p. 475.

6. Ibid.; p. 481. 
Impreso de Floridablanca, tenían fecundidades matrimoniales mayores que Asturias ${ }^{7}$. La reconstrucción y análisis de los Censos de Aranda y de Floridablanca para Asturias ${ }^{8}$ me ha permitido concluir que en la época de estos censos los matrimonios eran un 14,94 por ciento más fecundos en Asturias que en España como conjunto ${ }^{9}$, a pesar de que, también en Asturias, la nupcialidad femenina era un 9,01 por ciento menor que la del promedio de España.

Los datos contenidos en una publicación del año $1985^{10}$, que se presentaron en el IV Ciclo de Estudios Históricos de Cantabria celebrado en mayo de 1982, corresponden a un recuento de los números anuales de bautismos, matrimonios y entierros de mayores de nueve parroquias rurales asturianas. Con ellos se calcularon, por mínimos cuadrados, las rectas de regresión correspondientes al conjunto poblacional estudiado, con las que, para una población en el año $1768^{11}$ de 6885 habitantes, pude calcular unas Tasas Brutas de Natalidad (TBN), Nupcialidad (TBNU) y Tasa Bruta de Mortalidad de Mayores (TBMM) de 38,35; 8,52 y 15,96 sucesos, respectivamente, por mil habitantes. Lo más interesante de estos valores, cuyos cálculos los he rehecho ahora utilizando las ecuaciones de las rectas reseñadas en la citada publicación, es que conducen, si se divide el dato de la TBN por el de la TBNU, a «un número promedio de nacimientos por matrimonio celebrado de 4,50», número que, calculado así, en nuestra experiencia es siempre del orden de un 10 por ciento menor que el que se obtiene a partir de los números de hijos habidos divididos por el número de familias terminadas que los tuvieron. Estos dos datos me permitieron entonces apuntar que, muy probablemente, las familias asturianas que tuvieran hijos lo harían «en una cifra muy próxima a 5» en promedio ${ }^{12}$. Posteriormente, M. A. Fernández Ochoa, con 777 familias terminadas encontradas en el periodo de 1681 a 1830 en un colectivo poblacional del Concejo de Valdés ${ }^{13}$ obtuvo un promedio de 4,98 hijos habidos por familia con hijos. Es decir, Asturias era una región con elevada natalidad. Asturias, por otra parte, respondió al mecanismo del «descenso de la frecuencia y gravedad de las crisis de mortalidad a partir del año $1700 »$, cosa que es someramente conocida como consecuencia de los resultados de investigaciones realizadas sobre subconjuntos poblacionales asturianos de diferente tamaño ${ }^{14}$.

7. Ansón Calvo, M. C. Asturias en 1787: Demografia, Economía y Sociedad. Oviedo, 1992, p. 90

8. ANsón Calvo, M. C. Asturias en 1787: Demografia, Economía y Sociedad. Oviedo, 1992; El Censo de Aranda del Principado de Asturias (Su reconstrucción). Oviedo. 1997 y Asturias en la España de Carlos III, Demografia y Sociedad. Oviedo, 1998.

9. Ansón Calvo, M. C. Asturias en 1787..... p. 226.

10. ANsón CALvo, M. C., «Contribución al estudio de la demografia en Asturias durante los siglos XVII y XVIII». En: IV Ciclo de Estudios Históricos de Cantabria (Mayo de 1982). Santander, 1985, pp. 95-111.

11. Ansón Calvo, M. C. El Censo de Aranda... Oviedo, 1997, pp. 98-99.

12. ANSÓN CALVO, M. C. «Contribución al estudio de la demografia...». Santander, 1985, p. 103.

13. FERnÁNDEZ OCHOA, M. A. Luarca y la Tierra de Valdés: 1650-1830. Valdés, 1995.

14. ANES, G. Historia de Asturias, Edad Moderna II. El Antiguo Régimen: Economia y Sociedad. Gijón, 1977; SANZO FERnÁNDEZ, C. M. «La población de Asturias en los siglos XVII a XIX: Los Registros 
Antes de continuar, parece interesante debatir, en cierta medida, una cuestión relativa a la determinación de las crisis de mortalidad en general. Para los historiadores, el establecimiento del «momento temporal en que se produce una crisis de mortalidad» (dado que después del año 1610, año de expulsión de la minoría morisca, no se produce en España una disminución súbita de población por otra causa), en las épocas anteriores al comienzo de la recogida sistemática de los datos parroquiales de bautismos, matrimonios y entierros no se puede establecer por otro método que el que se podría llamar, «método documental histórico». Sin embargo, cuando los datos parroquiales ya existen, las actas de entierros «permiten localizar las crisis de mortalidad», aunque con la cortapisa de que, dado que en la mayor parte de los casos dichos registros no recogen los entierros de niños, alguna crisis se puede difuminar fácilmente si la mortalidad afectó fundamentalmente a la población infantil, es decir, se pueden localizar las crisis de mortalidad de mayores.

Evidentemente, crisis pequeñas de mortalidad de mayores pueden sno detener demasiado el crecimiento de la población», pero la determinación de si una crisis de mortalidad es «pequeña, mediana o grande» no es una cuestión baladí. Así pues, aunque aparentemente los datos parroquiales de entierros parecen, a priori, los más adecuados para «tratar cuantitativamente» las crisis de mortalidad, lo cierto es que difícilmente permiten un cálculo de la influencia futura de los excesos de mortalidad que «cualquier crisis» pudo tener, en tiempo y en cuantía, sobre la evolución de la población en la que se produjo.

Dado que esta es la situación, tendremos que partir de estos datos de registros parroquiales para analizar lo que le sucedió a la población rural asturiana a lo largo del siglo XVin, en relación con las crisis de mortalidad que pudo sufrir en dicha época. En principio, esta averiguación la centraremos en dos aspectos del problema: el primero, establecer la cuantía de población que creemos representa a la Asturias rural y, el segundo, elegir el método de determinación de localización temporal de las crisis y, dentro de cada una, de su cuantía relativa.

\section{DETERMINACIÓN DEL TAMAÑO DEL COLECTIVO POBLACIONAL QUE «MEJOR REPRESENTA» LA ASTURIAS RURAL}

Teóricamente, sólo el recuento de todos los datos parroquiales de entierros de todas las parroquias de Asturias proporcionaría la descripción real de la evolución de la mortalidad en la totalidad de la misma. Sin embargo, la suposición de que, muy probablemente, las enfermedades epidémicas o los efectos del hambre, al producirse, se extenderían fácilmente a todo su territorio, por otro lado de tamaño no demasiado

Parroquiales». Capitulo IV de: La economía española al final del Antiguo Régimen. I. Agricultura. Madrid, 1982; BARre:IRO Mallon, B. «La Demografia Asturiana en los Siglos XVI y XVII: Evolución y factores demográficos》s. En: Historia de Asturias, Tomo III, Edad Moderna. Gijón, 1978, pp. 1-17 y Ansón Calvo, M. C. «La Población Asturiana en el Siglo XVIII. Crisis demográficas. En: Historici de Asturias, Tomo IIl, Edad Moderna. Gijón, 1978, pp. 65-80. 
grande, permiten considerar que los valores de los datos parroquiales de cada una de sus 697 parroquias en un año determinado, serán «una especie de resultados experimentales fraccionarios» del total de la región. Si ello es así, los recuentos de los datos parroquiales, reducidos a una misma base poblacional (1000 habitantes, por ejemplo), no serán otra cosa que los resultados de tantos experimentos como parroquias se sometan a recuento y, cualquier resultado, se diferenciará del obtenido con los recuentos de otra parroquia, sólo por la conjunción aleatoria de las causas de la mortalidad en cada una. Por ello, vamos a suponer que la distribución de los datos será «la normal» y que, «estos datos», serán susceptibles de análisis estadísticos simples.

Si esto se cumpliera, la acumulación de recuentos de datos parroquiales sería permisible, aunque cualquier acumulación sin duda no conduciría a resultados de la misma validez desde el punto de vista de su representatividad del «total de Asturias». En este contexto, nuestra primera operación fue hacer los recuentos de los números anuales de entierros ( $\mathrm{y}$, de paso, de bautismos y de matrimonios) de un número suficientemente elevado de parroquias, cosa no siempre fácil, elegidas «lo más al azar» posible. Dado que, como hemos dicho, en el año 1768 había en el Principado 697 parroquias, escardamos entre ellas aquellas que tenían datos seriados entre los años 1701 y 1800 hasta recopilar el número de 67 parroquias. Sin embargo, de éstas, en tres casos, los datos de población del censo de Aranda que íbamos a utilizar en nuestro trabajo $^{15}$, aparecían sumados a los de las correspondientes «parroquias principales» de las que eran consideradas como «anexos», por lo que, realmente, los datos recogidos corresponden a 64 entidades de población.

Para determinar «cómo representan a Asturias Rural las 64 entidades de población recogidas», utilizamos los valores de sus Tasas Brutas de Mortalidad de mayores en el año 1768 ya que, de ser ciertos los supuestos de partida, el promedio de las mismas debiera ser «el mejor valor de esta magnitud» y «el límite de confianza de dicho promedio relativo a su valor» nos indicaría la corrección de los supuestos de partida. En el diseño de un experimento, cosa que es lo que hacemos al elegir el número y localización de las parroquias que vamos a acumular, este número debiera ser «suficientemente elevado para dar el número necesario de grados de libertad para la determinación de la precisión deseada» ${ }^{16}$. En nuestro caso, escogimos como «precisión exigida al resultado del experimento» la del 95 por ciento y, como índice de la misma, el valor del «límite de confianza del promedio de las Tasas Brutas de Mortalidad de Mayores de las entidades de población elegidas» calculado, también, con una precisión del 95 por ciento.

Continuamente, nos estamos refiriendo a los números anuales de entierros de mayores y sus correspondientes Tasas Brutas de Mortalidad (TBMM) dado que, desafortunadamente, en los casos analizados no hemos encontrado datos de números anuales de entierros de niños, como ya presumíamos.

15. Ansón Calvo, M. C. El Censo de Aranda... Oviedo, 1997, p. 34

16. Parratt, L. G., Probability and Experimental Errors in Science: An elementary survey. New York, 1961, p. 149. 
Una primera determinación de la TBMM promedio de este conjunto la llevamos a cabo con los datos de los «números reales de entierros de mayores» y los «valores de las poblaciones de cada entidad poblacional» para el año 1768. En la Tabla 1 aparece el promedio de los 64 valores de las correspondientes TBMM (TBMM1) juntamente con el de su «límite de confianza», calculado en base a 63 grados de libertad y una precisión del $95 \%{ }^{17}$. También aparece en la Tabla 1 la población conjunta de este colectivo de entidades y el número total de entierros de mayores del mismo. Así mismo, hemos llevado a cabo este mismo cálculo con las Tasas Brutas de Natalidad (TBN) del mismo colectivo de 64 entidades poblacionales y con las Tasas Brutas de Nupcialidad de 64 entidades de población aunque, estas últimas, no son exactamente las mismas entidades que las empleadas en los cálculos de las TBMM y TBN.

Analizando los valores de E1\% a que dan lugar los diferentes colectivos de datos, encontramos que, tanto en las TBMM1 como en las TBN1 y TBNU1 promediadas, los límites de confianza representaban entre el $8,60 \%$ y el $15,79 \%$ de los correspondientes promedios. De cualquier modo, nunca eran del orden del 5 por ciento o menores. Los resultados obtenidos indican que, con el método que hemos empleado para calcular «la mejor Tasa Bruta correspondiente», basado, simplemente, en dividir los números de sucesos contados en el año 1768 para cada entidad poblacional, por la población que se deduce del Censo de Aranda para la misma (valores de TB...1), no «existen los necesarios grados de libertad para la determinación de las mismas con precisión del 95\%». En este contexto, podemos indicar que, en el caso de los bautismos, en los que hemos llegado a recoger los datos de números anuales de bautismos para el año 1768 de 93 entidades poblacionales (el 13,34 por ciento de las 697), estos nos han conducido a un valor de TBN1 de $36,59 \pm 2,55$ y a un E1\% del 6,98\%, es decir, los casos promediados son todavía menos que los necesarios. A la vista de lo obtenido, se podría pensar que quizás las distribuciones de datos originales tienen condicionantes distintos al del simple tamaño de la muestra que las convierten en «no totalmente normales», exigencia fundamental subyacente en todo el análisis estadístico realizado. Este resultado revela que la elección del número adecuado de parroquias para contar sus entierros anuales e, igualmente, sus números de bautismos o de matrimonios, no es un asunto baladí.

Ante esta situación, considerando que el número anual de entierros, o de bautismos o de matrimonios generados en un año en una entidad poblacional determinada es quizás también una consecuencia de la historia demográfica de dicha población, que modula mucho su comportamiento en un momento determinado, pensamos que con los datos de «menos» entidades de población, posiblemente se obtendrían valores más adecuados de los números de cada suceso en el año 1768, si tuviéramos en cuenta este hecho y utilizáramos para los cálculos de las TB... los valores de números de sucesos que proporcionan las rectas de tendencias calculadas para el periodo temporal entre los años 1701 y 1800 . En el fondo, hacer el cálculo de esta forma, representa realizar un suavizado de los datos originales.

17. Mickley, H. S.; SherwoOd, T. K. y ReED, CH. E., Applied Mathematics in Chemical Engineering. New York, 1957. 
Tabla 1

Valores de Mortalidad de Mayores (TBMM), Tasas Brutas de Natalidad (TBN) y de Nupcialidad (TBNU) de distintos colectivos poblacionales de Asturias Año 1768

\begin{tabular}{|c|c|c|c|c|c|c|c|}
\hline Colectivo & Poblac 1768 & $\mathbf{N}^{\mathbf{0}}$ E(M). 1768 & TBMM1 & E1\% & TBMM2 & E2\% & TBM3 \\
\hline 64 entida. & 35798 & 455 & $12,43+1,96$ & 15,79 & $13,74+0,78$ & 5,71 & 13,57 \\
\hline & & & & & & & \\
\hline Colectiv0 & Poblac 1768 & $\mathbf{N}^{0}$ Baut. 1768 & TBN1 & E1\% & TBN2 & E2\% & TBN3 \\
\hline 64 entida. & 35798 & 1271 & $36,72+3,16$ & 8,60 & $37,61+1,48$ & 3,94 & 36,40 \\
\hline & & & & & & & \\
\hline Colectivo & Poblac 1768 & $\mathbf{N}^{0}$ Matr. 1768 & TBNU1 & E1\% & TBNU2 & E2\% & TBNU \\
\hline 64 entida. & 36090 & 275 & $7,92+1,18$ & 14,97 & $8,00+0,39$ & 4,90 & 7,71 \\
\hline
\end{tabular}

* Estas 64 entidades no son exactamente las mismas que en los casos de los entierros de mayores y de bautismos, debido a que, en un caso, el de la parroquia de Mieres, apareció un hueco importante en los datos de matrimonios. Mieres se sustituyó por otra parroquia.

Con estos condicionantes, calculamos los valores de las Tasas Brutas de Mortalidad de Mayores, de Natalidad y de Nupcialidad para cada entidad poblacional que forma parte del colectivo correspondiente, a partir de los «mejores valores de los bautismos, $o$ de entierros de mayores, o de matrimonios, en el año 1768, procedentes de las rectas de mínimos cuadrados representativas de la tendencia de los bautismos (o de entierros o de bodas) del mismo»». Las rectas de tendencia se calcularon con 100 valores de números anuales de sucesos (de los años 1701 y 1800) en todos los casos. En la Tabla 1, como TBN2 aparecen los valores de los promedios de las Tasas Brutas calculadas así para cada colectivo, acompañados de los correspondientes «límites de confianza de las medias» calculados con una precisión del 95\%. En la Tabla 1 los valores de E2\% son los tantos por cientos que estos límites de confianza representan frente a sus correspondientes promedios.

Respecto a la fiabilidad de los valores de TBN2 (E2\%), de los resultados que aparecen en la Tabla 1 se deduce que a partir de la acumulación de 64 entidades poblacionales, ésta se cumple adecuadamente, es decir, dentro de la condición exigida del $95 \%$, en los casos de los datos de bautismos y de matrimonios, pues las E2\% correspondientes, están fuera de la precisión exigida a priori al experimento, al ser menores del 5 por ciento de los correspondientes promedios. A la vista de todos estos resultados, se podría decir, que desde 64 entidades de población, la acumulación de los números anuales de bautismos representa bien el comportamiento de Asturias Rural en cuanto a la natalidad, siempre que se traten por el método descrito, y que también lo hacen en cuanto a la nupcialidad. Ahora bien, con las 64 entidades de población en las que hemos acumulado sus entierros de mayores que, de paso, son las mismas en las que hemos acumulado los de bautismos, la representatividad del colectivo rural asturiano así obtenido no es tan buena. Los números anuales de entierros de mayores de las 64 entidades 
de población, tratados según la metódica descrita, conducen a una TBMM2 promedio y límite de confianza de la media de $13,74 \pm 0,78(\mathrm{E} 2 \%=5,71 \%)$, tasa que, como se ve por el valor de E2\%, «es menos precisa», aunque no demasiado (dentro del $96 \%$ ), que la TBN2 del mismo colectivo (E2\% $=3,94)$. Con los datos de matrimonios de un colectivo de 64 entidades de población, algo diferente, como ya dijimos que el formado para el análisis de los datos de bautismos, obtuvimos como resultado el que aparece en la Tabla 1, una TBNU2 de 8,01 $\pm 0,39(\mathrm{E} 2 \%=4,85)$, es decir, dentro de la precisión buscada. La conclusión es que, en relación con la mortalidad de mayores, las 64 entidades de población elegidas no son estadísticamente suficientes para «extender a toda Asturias Rural» su TBMM2 con la precisión exigida a priori.

A pesar de lo que acabamos de exponer, dadas las dificultades que hemos encontrado para recoger datos de «mayor número de entidades de población», como la precisión encontrada en el caso de los entierros no es tan mala, en los análisis conducentes a la determinación cualitativa y cuantitativa de las crisis que sufrió la población asturiana a lo largo del sigio XVIII, vamos a emplear los datos acumulados de entierros de mayores y de bautismos de estas 64 entidades de población, aunque siempre consideraremos de "más confianza» los resultados que se deduzcan de los datos de bautismos. En la Tabla 1 se dan también, para juzgar sobre su representatividad, los valores de las Tasas Brutas procedentes de los «datos acumulados» de bautismos, de entierros de mayores y de matrimonios (estos son los que aparecen como TB...3), calculados para el año 1768 , a partir del empleo de las respectivas rectas de tendencias de «los totales» de los números anuales de las correspondientes actas parroquiales. Como puede comprobarse, ambos valores están dentro de los límites de confianza de las TBN2 promedio, respectivas $(36,13$ por abajo y 39,09 por arriba en los bautismos y 7,61 y 8,39 en los matrimonios). A pesar de que el valor de la TBMM3 que se obtiene con «los números anuales de entierros de mayores de todo el colectivo de 64 entidades de población» $(13,57)$ también está dentro del límite de confianza del promedio de la TBMM2 (12,96 por abajo y 14,52 por arriba) su fiabilidad, como ya hemos dicho, no es tan buena. En todos los casos, los resultados obtenidos de TB..3, están dentro de las horquillas de los E2\% correspondientes, es decir, son tan representativos de las correspondientes Tasas Brutas como los valores de TB..2. Las TBN3 y TBNU3 que aparecen en la Tabla 1, calculados con los «mejores valores» de bautismos y de bodas en el año 1768 (rectas de mínimos cuadrados), serían las que podríamos llamar mejor Tasa Bruta de Natalidad $(36,40)$ y mejor Tasa Bruta de Nupcialidad (7,71) de Asturias en el año 1768.

\section{CRISIS DE MORTALIDAD EN LA ASTURIAS RURAL}

Con los datos de números anuales de entierros de mayores de las 64 entidades de población que, con una precisión aceptable, representan la mortalidad de la Asturias Rural, hemos construido la Figura 1, en la que se ve el transcurso, a lo largo del siglo XVIII (entre 1701 y 1800), de su mortalidad de mayores. En esta figura, además de los datos originales de entierros de mayores, aparece la «mejor línea, calculada por mínimos cuadrados, de la tendencia temporal de los mismos»y, también, las líneas que 


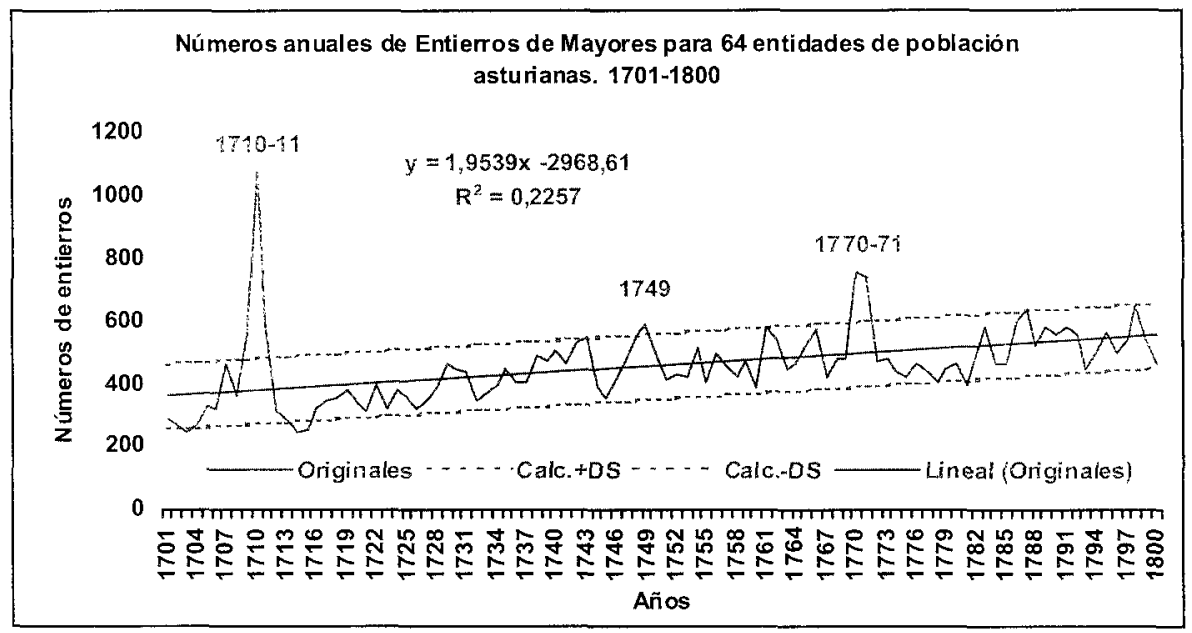

Figura 1

acotan, por arriba y por abajo, la desviación estándar entre los valores empíricos y los calculados. Estas líneas, de algún modo, indican los casos anormales de entierros. Así, hemos marcado éstos con la fecha de su aparición. A este nivel de análisis podríamos decir que, a lo largo de la centuria, sólo hubo mortalidades anormales en los años 1710-11, 1749 y en el bienio 1770-71. En la Figura 1 aparece también la ecuación de la línea de tendencia, de pendiente positiva $(+1,9539)$, lo que no significa, en principio, otra cosa que un aumento de la mortalidad como consecuencia del crecimiento de la población del colectivo. Lo encontrado, aunque sólo sea someramente, indica lo tantas veces dicho sobre la práctica desaparición en el siglo XVIII de las fuertes crisis de mortalidad, que sufrían las poblaciones en siglos anteriores. Aún así, un cierto tipo de mortalidad basal se mantuvo bastante constante durante este siglo, lo que nos llevaría a la conclusión de que la TBMM3 antes calculada es, casi con seguridad, una buena Tasa Bruta Basal de Mortalidad de Mayores.

Podemos sin embargo apuntar que este método de determinar los años en que se producen mortalidades anormales (crisis de mortalidad) es bastante «grosero». Existen sin embargo métodos «más finos» de hacerlo. De los existentes hemos elegido la variante del método de Dantí (Jaume Dantí, Terra i Població... 1988, p. 106-108), también adaptado por Valentí Gual (Valentí Gual, Les crisis de mortalitat... Miscel-lania..., 24, 1993, p. 57-58), según lo describen Gual y Millas ${ }^{18}$ (Xavier Gual i Remírez y Carles Millás i Castellvi, Olesa de Montserrat en época dels Austria. Demografía i Societat, 2002, p. 98). Aplicándolo sobre los datos de entierros de mayores, entre 1701 y 1800 ,

18. Gual i Remirez, X. y Carles Millás i Castellvi, C. «Olesa de Montserrat en época dels Austria. Demografía i Societat. PAM. Barcelona, 2002, p. 98. 


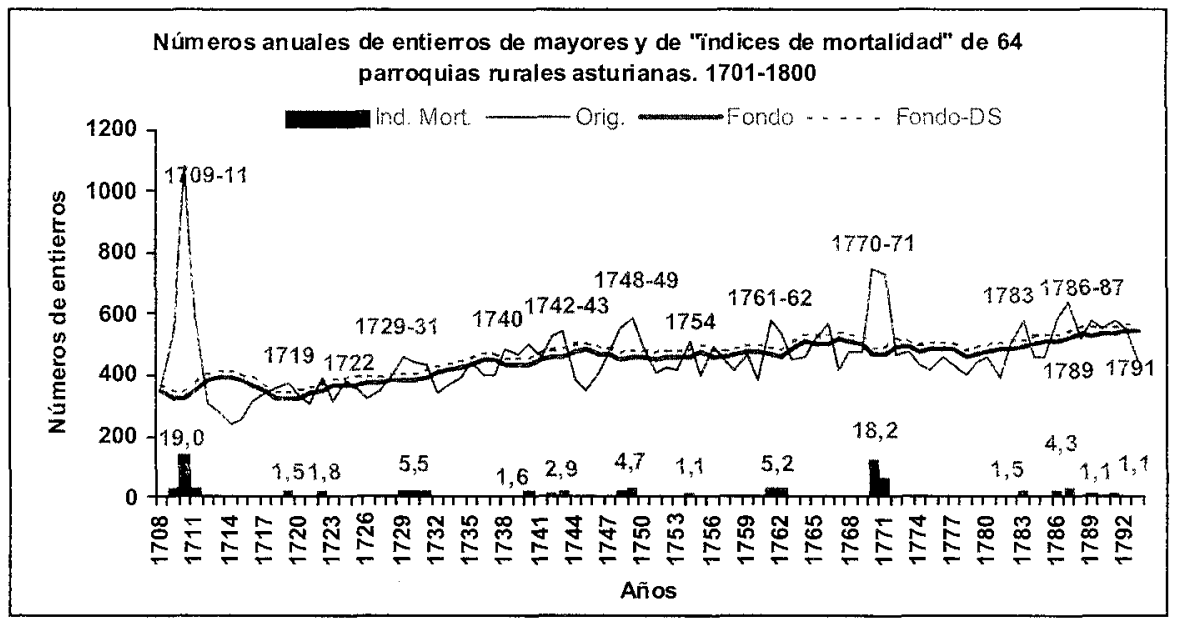

Figura 2

del tantas veces citado colectivo de 64 entidades de población asturiana, resultan las crisis que se destacan en la Figura 2.

El espacio temporal de análisis que aparece en la gráfica 2, va de los años 1708 a 1793, ya que al aplicar este método de análisis «se pierde», por así decirlo, información sobre la mortalidad de 14 años, los siete iniciales y los siete finales del periodo estudiado (100 años de datos). Lo interesante de la gráfica es que, a pesar de su mayor finura de análisis, el método empleado reconoce muy pocas crisis de mortalidad destacadas en la centuria. Las barras verticales de la gráfica miden la «intensidad» de cada crisis detectada, crisis que, aparentemente, son muchas. El año, o años, de actuación de cada una aparece también en la gráfica. De forma cualitativa, Gual y Millas ${ }^{19}$ (Xavier Gual i Remírez y Carles Millás i Castellvi, Olesa de Montserrat en época dels Austria. Demografia i Societat, 2002, p. 98) proponen las siguientes denominaciones, siguiendo a Dupâquier, para las intensidades de las crisis: Menor, si la intensidad va de 1 a 2 , Media, si va de 2 a 4, Fuerte, si va de 4 a 8 , Importante, si va de 8 a 16, Gran Crisis, si va de 16 a 32 y, finalmente, Catástrofe, si va de 32 en adelante. Aplicando estas denominaciones en nuestro caso, de las 23 crisis individuales detectadas (realmente sólo son 14 si se acumulan los valores de las producidas en años sucesivos), únicamente dos, la de los años 1709-1710-1711 y la de los años 1770-1771, son «grandes crisis», las cuatro de los años 1729-1730-1731, 1748-49, 1761-62 y 1786-87, se podrían calificar como de «crisis fuertes». La de los años 1742-1743 sería una «crisis media» y, el resto, siete crisis individuales, las de los años 1719, 1722, 1740, 1754, 1783, 1789 y 1791 , habría que calificarlas como de tipo «menor». Las dos grandes crisis, una de tres años

19. Ibid.; p. 98 . 
de duración y otra de dos años, sin duda tuvieron que producir efectos duraderos en la población asturiana, cosa que no será tan evidente en el caso de las cuatro fuertes ni en el de la de grado medio. Por otro lado, sería de esperar que las crisis de tipo menor no produjeran efectos destacables. Ahora bien, de los simples valores de su intensidad, en la forma en que la hemos calculado, no es posible deducir la cuantía de dichos efectos.

Teóricamente, las repercusiones de las crisis de mortalidad detectadas en la población sobre la que actuaron serían fácilmente calculables, si existiera una «mortalidad de base constante» sobre la que las crisis lo único que harían sería exacerbarla en los años en que se produjeron. Este comportamiento significaría, en nuestro caso, que existiría una proporcionalidad entre mortalidad de mayores y población a lo largo del tiempo, o sea, significaría una cierta constancia de la Tasa Bruta de Mortalidad de Mayores. Tal cosa, sin embargo, está muy lejos de ser cierta, como muestran los resultados gráficos contenidos en la Figura 3.

La correlación $\left(\mathrm{R}^{2}\right)$ entre números totales de entierros de mayores de las 64 entidades de población que representan razonablemente a la Asturias Rural y las fechas en que se produjeron es 0,2257 , es decir, muy baja, lo que, creemos, indica una «pobre constancia de la mortalidad basal a lo largo del tiempo durante el siglo XVIII). Este resultado es lógico, pues la muerte es un proceso muy aleatorio, determinada por muchas causas distintas. Es interesante decir que si se eliminan los datos de los años 1709 a 1711 y de 1770 a 1771, la correlación mejora bastante, pero no demasiado, ya que pasa a ser de 0,5623 . Así pues, a partir de los puros datos de los números de entierros de mayores (aunque creemos que sucedería lo mismo si los datos utilizados fueran los de entierros de mayores más niños), no es posible obtener cifras fiables de los cambios poblacionales que acompañaron a las crisis. Sin embargo, la natalidad

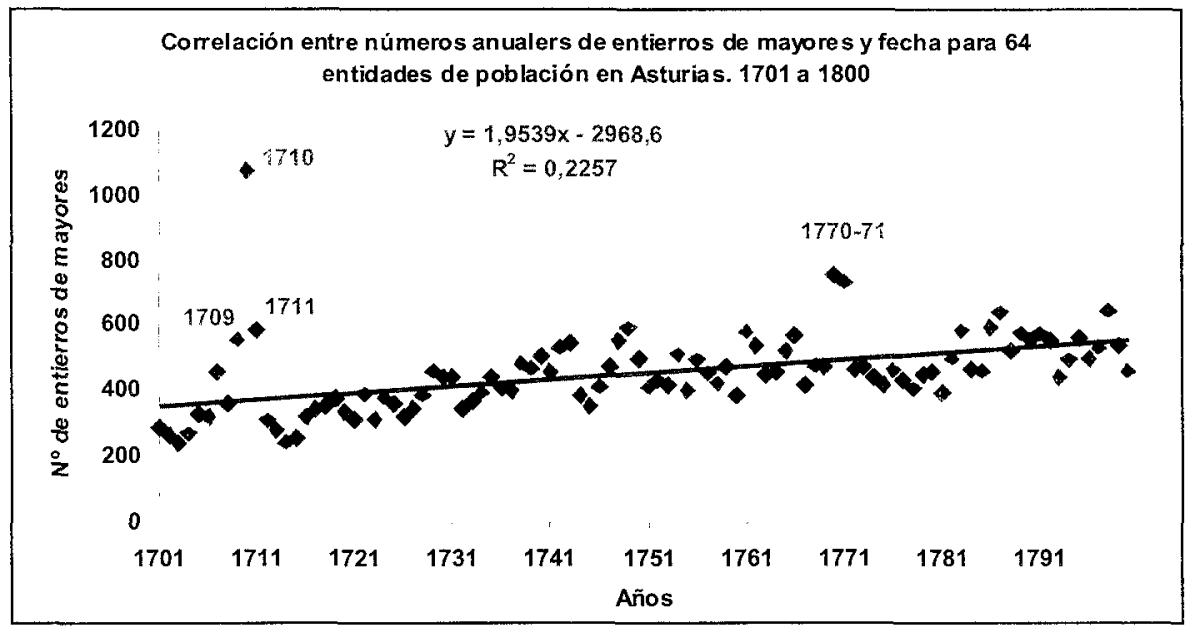

Figura 3 


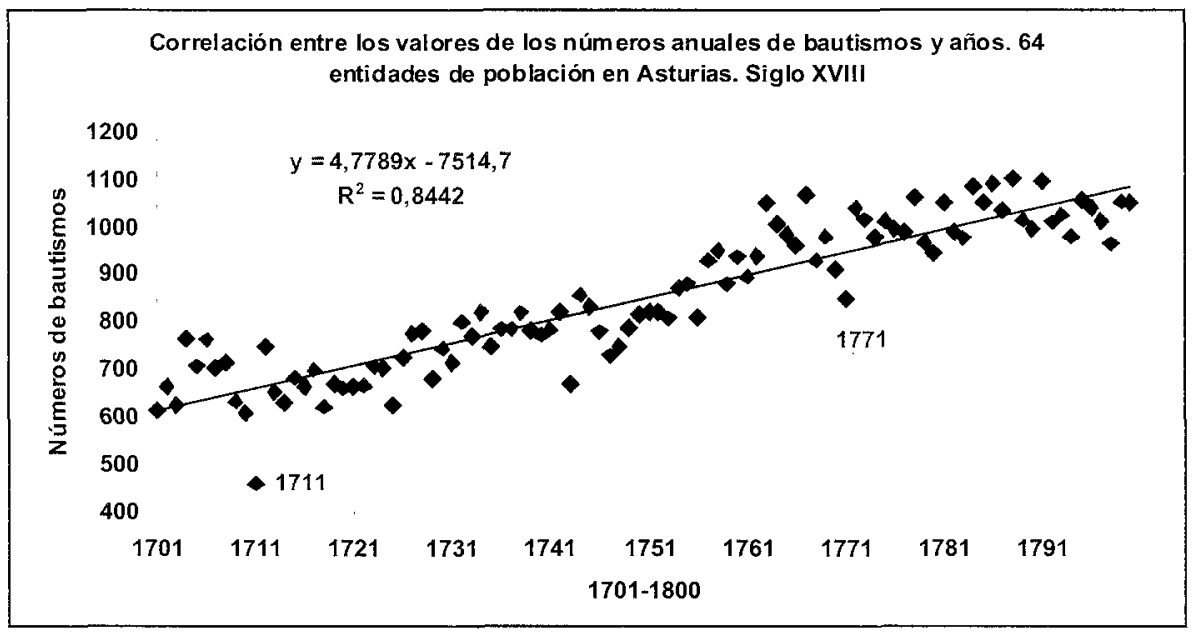

Figura 4

basal es «mucho menos dependiente de variadas causas externas» aunque, como es lógico, las crisis de mortalidad actuarán sobre ella. En este sentido, es de esperar que exista una «buena constancia de la natalidad con el tiempo», cosa que los datos de la Figura 4 ponen de manifiesto. En ella se ve que entre los números anuales totales de bautismos y fechas para las mismas 64 entidades de población de Asturias para las que hemos contado los entierros de mayores, existe una «buena correlación», al menos mucho mejor que la que existe entre números anuales totales de entierros de mayores y fechas, pues es de $0,8442\left(\mathrm{R}^{2}\right)$. Esta pasa a ser, si se eliminan los años de natalidades «anormales» de 1711,1743 y 1771 , de 0,8573 .

En el mejor de los casos, cuando se suprimen los datos de las crisis de mortalidad importantes y de las natalidades anormales por bajo de los mismos años, la correlación de los entierros de mayores con las fechas es «bastante peor» que la de los bautismos, de acuerdo con lo que opinan algunos demógrafos ${ }^{20}$ con relación a que «la tasa bruta de natalidad no cambió desde el siglo XVII hasta hace escasos años». Parece evidente que puede aceptarse que la TBN del colectivo de las 64 entidades de población asturianas, que hemos tomado como base para nuestro estudio, también se debió conservar constante a lo largo del siglo XVIII. Tal cosa no la podemos comprobar, pues excluyendo el censo de 1768 , no existe entre los años 1701 a 1800 otro Censo de Población para el Principado tan pormenorizado como éste. Se podría aducir que los datos del Catastro de Ensenada pueden dar valores de población de los Concejos Asturianos, o que a través de los Padrones de Moneda Forera (existentes en no todos Concejos), podrían aproximarse cifras para las poblaciones de las entidades (parroquias) que hemos acu-

20. Cox, P. R. Demography. Cambridge, 1970 , p. 387 y sig. 


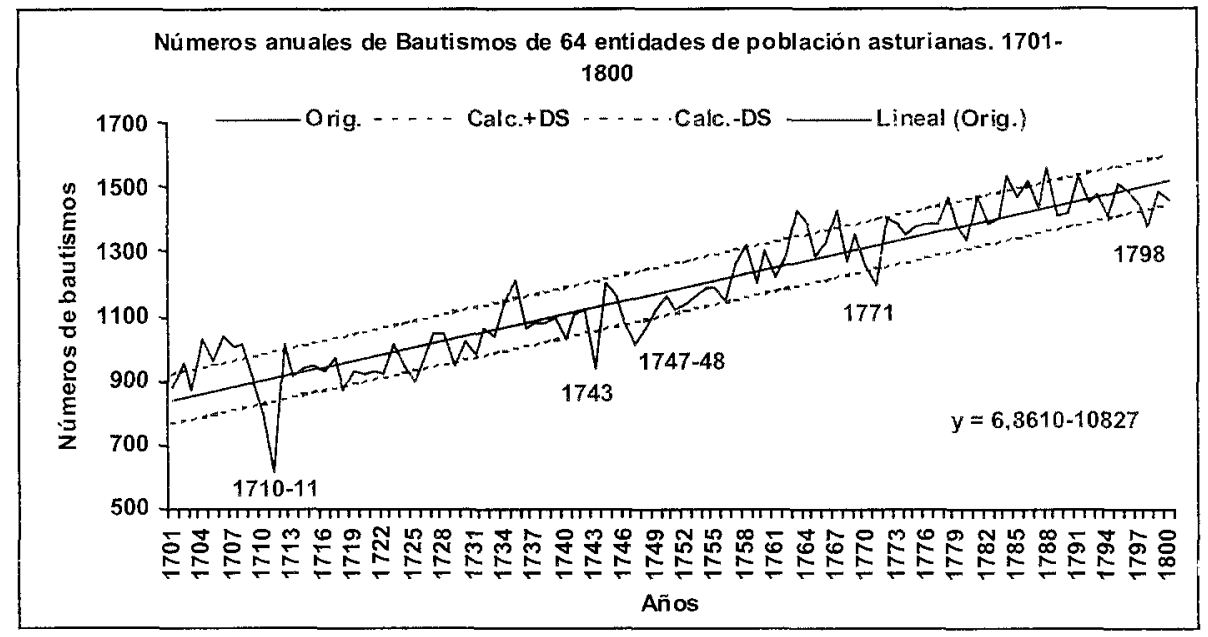

Figura 5

mulado pero, aunque existieran tales Padrones para todas ellas, la necesidad de utilizar un coeficiente de conversión de vecinos en habitantes, cuya determinación es muy aleatoria, conduciría a que los datos finales fueran de menos confianza que los procedentes del censo del año 1768. Por todo ello, vamos a aceptar como cierta la hipótesis de trabajo de la constancia de la Tasa Bruta de Natalidad y emplear la que aparece en la Tabla 1 para calcular la influencia que en la población tuvieron las distintas crisis de mortalidad antes reseñadas.

\section{EVOLUCIÓN DE LOS NÚMEROS ANUALES DE BAUTISMOS}

Como acabamos de explicar, los datos sobre la evolución temporal de la población de la Asturias Rural representada por las 64 entidades poblacionales que, hasta ahora, hemos manejado, los vamos a obtener de un análisis de los datos de los números anuales de bautismos que, estas entidades, generaron entre los años 1701 y 1800. Los resultados obtenidos, expresados en forma relativa sobre su población de 35798 habitantes, que representaban el $10,45 \%$ de los 342.537 habitantes que sumaba la población de Asturias en el año $1768^{21}$, lo vamos a extender a «toda Asturias». Este colectivo, como se puede deducir de los datos contenidos en la Tabla 1, representa perfectamente a la citada Asturias Rural, con lo que para calcular crecimientos o disminuciones de población, una vez aceptada la hipótesis de partida de que los números anuales de bautismos y la cuantía de la población que los genera son proporcionales o, lo que es lo mismo, que durante el periodo de tiempo de observación la Tasa Bruta de Natalidad

21. Ansón Calvo, M. C., El Censo de Aranda... Oviedo, 1997, p. 34. 
de la población se mantuvo constante, lo único que tendremos que determinar es cómo evolucionó su natalidad con el transcurso del siglo.

La Figura 5 recoge los datos originales de los números anuales de bautismos a lo largo del periodo de 1701 a 1800 . En ella, junto con la recta de tendencia, que, por el valor de su pendiente, revela un crecimiento elevado de la población implicada, aparecen también las líneas «pendiente \pm DS» que ahorquillan dicha pendiente. La DS calculada representa el $\pm 6,43 \%$ ( $\pm 74,33$ bautismos) del promedio de 1156 bautismos correspondiente a los 100 años estudiados. Como primera aproximación al problema de determinar los «años anormales, por menos, de bautismos», podríamos considerar que, éstos, son aquellos que el valor de su número anual está fuera de la línea inferior «pendiente-DS». En mi opinión, son los señalados en la Figura 5 con la fecha de su aparición. Ahora bien, la determinación «de visu» es bastante «grosera», situación que también hemos señalado se daba en el caso de los datos de entierros de mayores.

Con el fin de afinar la localización de estos números anormales de bautismos, pensamos que quizás el mismo método empleado para localizar y cuantificar los años de crisis de mortalidad, se podría emplear en el caso de los bautismos, sin más que sustituir los valores «por más sobre el fondo» calculados en el caso de los entierros, por los valores «por menos bajo el fondo» en el caso de los bautismos. En el cálculo de dicho fondo hemos utilizado la metodología que la referida en el caso de los entierros. No conocemos si este procedimiento de cálculo se ha empleado con el propósito con que ahora lo utilizamos pero, en principio, no existe inconveniente teórico alguno en ello. La Figura 6 resume los resultados obtenidos.

Como resultados de este trabajo sobre los números anuales de bautismos, hemos encontrado un caso de «bajos valores acumulados», que se podría calificar de «descenso importante», en los años 1710-1711, tres casos, 1743, 1746-1748 y 1770-1771

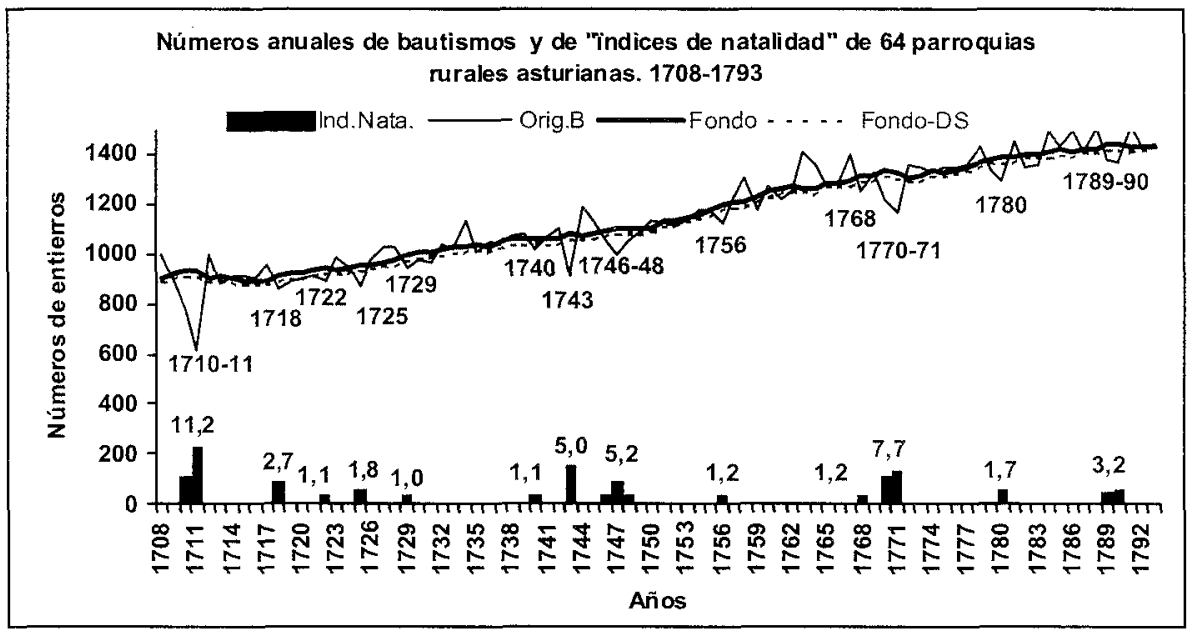

Figura 6 
de «descensos fuertes», dos casos de «descensos medios», en los años 1718 y bienio 1789-1790, siendo el resto, siete casos $(1722,1725,1729,1740,1756,1768,1780)$, del tipo «descenso menor». Aquí, al igual que en los casos de las crisis de mortalidad, hemos empleado la terminología de Dupâquier para calificar los descensos. Los hallazgos de los años 1710-1711 y 1770-1771 tienen un origen evidente, «las crisis importantes de mortalidad antes halladas», sin embargo, el descenso de bautismos del año 1743 no se corresponde muy bien con las crisis de mortalidad de la misma época representadas en la Figura 2. Esta afirmación se ve claramente representada en la Figura 7, en la que aparecen, en forma acumulada, los índices de mortalidad de mayores y descensos de natalidad para el mismo colectivo de las mismas 64 entidades de población de la Asturias Rural. Los descensos en bautismos, con un retraso de un año, es decir, el índice más elevado de mortalidad se adelanta un año al más bajo de los índices de natalidad, aparecen en el bienio 1710-1711 y en el bienio 1770-71. Como los datos de números anuales de entierros no incluyen los entierros de niños, este desfase no corresponde a otra cosa que a la muerte de mujeres pregnantes. En el caso del descenso medio en bautismos del año 1718, éste quizás se podría achacar a la muerte, en los años 1709 a 1711, de «jóvenes solteros» que, posteriormente, no se casaron. El caso más extraño lo genera el «descenso fuerte de bautismos» del año 1743 pues parece difícil poder achacarlo a las mortalidades en exceso de los años 1729 a 1731, 1740 y 1742-1743, mortalidades que, respectivamente, son de tipo fuerte, menor y de tipo medio aunque, bien es verdad que su acumulación a lo largo de 15 años (1729 a 1743) podría dar lugar a lo hallado. Sin embargo, personalmente creo que, este bajo valor de bautismos, se debe en gran medida a los «niños seguramente muertos» en la crisis de mortalidad importante de los años 1709 a 1711 , y los que «no nacieron» en los años inmediatamente siguientes a tal crisis, bajo valor que se refleja, 30 años después, en un descenso acusado de la natalidad.

Utilizando los índices acumulados de mortalidad en el sentido antes comentado, la «gran crisis» de los años 1709-1711 (Figura 7) produce «un descenso de natalidad importante» en los años 1710-1711 y la de los años 1770-1771 «un descenso de natalidad fuerte» en sus mismos años. Por su parte, «la crisis fuerte» del trienio de 17291731, probablemente es co-responsable del «descenso de natalidad igualmente fuerte» del año 1643 (distante 13 años de ella) y, quizás, del «igualmente fuerte descenso de natalidad» del trienio 1747-1749 (17 años), aumentado quizás por la «crisis fuerte de mortalidad» de los años 1748-1749. Es muy interesante comentar que la «gran crisis» de los años 1770-1771 no se traduce, unos años más tarde (13 años), en un descenso acusado de bautismos, lo que quizás podría revelarnos que generó pocos muertos entre los «jóvenes solteros». Por otro lado, la existencia en el mayor de los casos de descensos de natalidad «menores», refleja el hecho de que las crisis de mortalidad pequeñas «se compensaron pronto», lo que se traduce en recuperaciones rápidas de la población. Teniendo en cuenta que el 50 por ciento de las crisis de mortalidad encontradas a lo largo del siglo XVII en Asturias son de tipo «menor», que el 28,6 por ciento son de tipo «fuerte», el 7,1 por ciento de tipo «medio» y el 14,3 por ciento de tipo «importante», no es extraño que su población creciera mucho a lo largo de este siglo. 


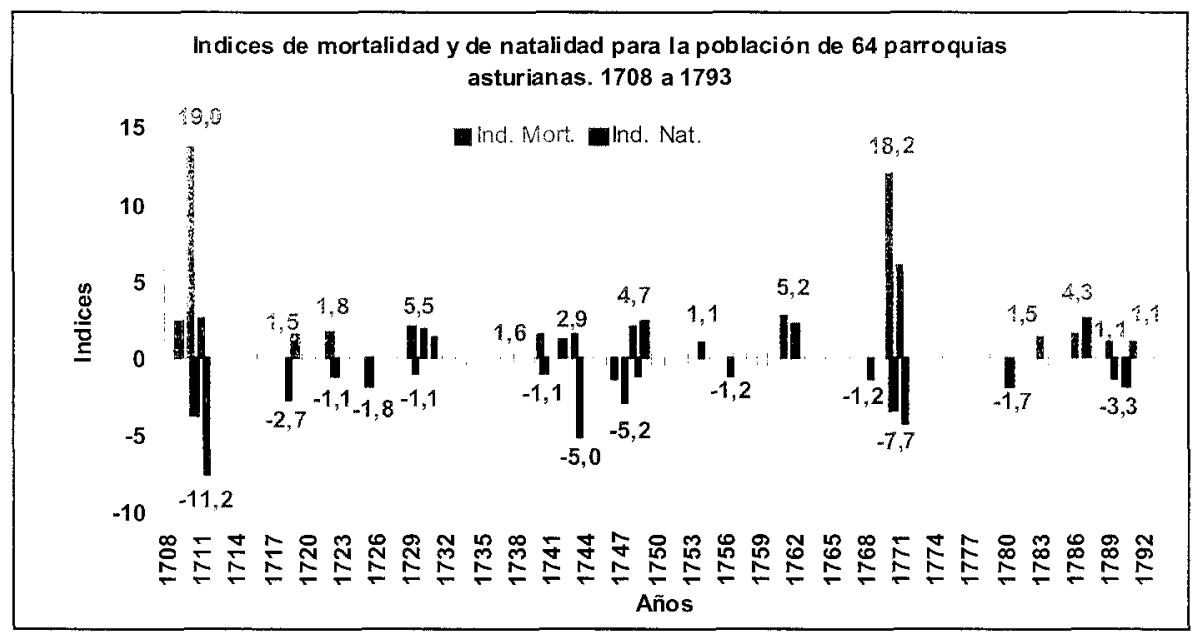

Figura 7

Sin embargo, el análisis hecho hasta ahora no nos permite cuantificar la influencia de estas distintas crisis en el crecimiento o descenso de la población, ya que, para ello, debemos analizar de otro modo la evolución secular de los números anuales de bautismos del colectivo. Si se emplean los datos originales de bautismos (884 y 1458) y la TBN que resulta de dividir los 1271 bautismos que, en conjunto, generaron las 64 entidades de población en el año 1768, por los 35798 habitantes del colectivo en el mismo año, tasa que es de 35,50 por mil habitantes, resulta un crecimiento de población en el mismo periodo del 64,93 por ciento $(5,07$ por mil anual, como valor del crecimiento anual sostenido correspondiente). Por otro lado, con los datos de la recta de tendencias de bautismos de la Figura 5 y considerando constante a lo largo del siglo XVIII la Tasa Bruta de Natalidad del colectivo estudiado e igual en valor al dado en la Tabla 1 (TBN3=36,40 nacimientos por mil habitantes) para el año 1768 , entre 1701 y 1800 (99 años), el crecimiento de la población en el colectivo empleado para representar la Asturias Rural fue del 80,54 por ciento del valor de la población en el año 1701, lo que corresponde a un crecimiento anual sostenido del 5,99 por mil anual. Este último aumento se basa en la hipótesis de que la tendencia de crecimiento de la población fuera única, y que la línea recta es la mejor representación de dicha tendencia. Aparecen pues diferencias del 24 por ciento en los crecimientos, según se empleen los datos originales o los calculados con la recta de mínimos cuadrados. Por otro lado, conviene recordar que la precisión con que la recta de la Figura 5 representa los datos de partida es del $\pm 6,43$, expresada como tanto por ciento de la misma respecto al promedio de los datos calculados.

Observando las formas de evolución con el correr del siglo de los datos de partida (Figura 5), parece que hay intervalos temporales en los que la recta de tendencia 
obtenida por mínimos cuadrados los representa mejor y otros en los que los representa peor, por lo que, quizás, esta única recta no sea la mejor representación de los mismos y que una línea quebrada, por llamarla de algún modo, podría hacerio mejor. En relación con lo que ahora nos ocupa, hay que decir que el «índice de precisión» del 6,43 está fuera del que, a priori, exigimos en todos nuestros cálculos ( 5 por ciento), por lo que hemos investigado si era posible «mejorar la representación de la evolución temporal de dichos datos», sofisticándola más.

Como hemos dicho, observando la Figura 1 se ve claramente que la recta de tendencia se acerca en unos casos más y en otros menos a lo que, de visu, sería la evolución temporal de los datos originales. Esto se debe a que, si bien la TBN se mantiene constante, no lo hace la cuantía de la población que la produce, precisamente como consecuencia de los efectos de las crisis de mortalidad. En consecuencia, a fin de mejorar el análisis de los datos de bautismos en cuanto al establecimiento de los periodos inter-crisis en los que la TBN sí se mantuvo estacionaria, hemos aplicado a los datos de números de bautismos la metódica de análisis de los mismos que describimos y utilizamos en un trabajo sobre las consecuencias que produjo la Guerra de la Independencia sobre la población asturiana ${ }^{22}$.

En principio, el método es perfectamente conocido y se basa en la aplicación de la estadística a los resultados de las «medidas experimentales» de las magnitudes en estudio (números anuales de bautismos del colectivo formado por 64 entidades de población como medidas, en cada año, de la cuantía de su población que mantenía constante su TBN). Sin embargo, de cada medida sólo podemos disponer de un valor, pues no podemos repetir el experimento, y sobre un valor no es posible establecer estadística alguna. Para obviar este inconveniente hemos dividido los datos anuales de bautismos en grupos según periodos de varios años (cohortes), hemos calculado las medias aritméticas de las cohortes y los valores de los correspondientes «límites de confianza» de cada media y hemos comparado, a lo largo de todo el siglo XVIII, mediante un Test F, las «medias y límites de confianza de las medias de cada periodo temporal» con los correspondientes al periodo posterior. Los límites de confianza de las medias se calcularon con el «criterio estadístico» del 95 por ciento y el mismo criterio se aplicó al «test F».

La aplicación del Test $F$ es, en principio, un método irreprochable para juzgar sobre la pertenencia, o no, a la misma distribución estadística, de las medias de dos series de medidas de una misma magnitud. Sin embargo, el resultado es un diagnóstico tipo si/no. Ahora bien, en la investigación que estamos llevando a cabo, es necesario traducir este resultado, no sólo a determinar los «cambios de población» que dieron lugar a los «periodos de población estacionariamente creciente o decreciente» sino que, además, si es posible, a dirigir la búsqueda de las razones históricas que los propiciaron. Es decir a encontrar además del cuánto, el cómo y, si es posible, cosa más

22. Anson CALvo, M. C., «La Guerra de la Independencia en Asturias: Repercusiones Demográficas». I Jornadas sobre la Guerra de la Independencia en Málaga y su Provincia. Málaga, 2002. En prensa. 
dificil, algo sobre el porqué. En este sentido, si se pudiera determinar como se produjo dicho cambio súbito de población, quizás la utilidad del método empleado fuera mayor. En este sentido, pensamos que sí podríamos deducir algo más sobre cómo se produjo el salto, analizando la forma como interrelacionan los valores de los límites de confianza de las medias implicadas en el Test F.

Dado que para determinar los «cambios de tendencias en el crecimiento de la población», comparando medias de cohortes de datos de bautismos, tiene importancia el año en que se comienzan los recuentos de números anuales de este tipo de dato y los tamaños de las cohortes empleadas, con el fin de encontrar cual es la mejor clase de cohorte (desde la de 6 a la de 15 datos) con que la metodología diseñada pondría de manifiesto los «cambios de tendencias de crecimiento», teniendo en cuenta los anormalmente bajos números anuales de bautismos de los años 1710-1711 y 1770-1771, llevamos a cabo el análisis de los 100 datos disponibles en tres partes, realmente en dos, con todos los tipos de cohortes citados, una con los 58 datos de números de bautismos correspondientes a los años 1712 a 1769 y otra con los 29 datos de los años 1772 a 1800. En los dos intervalos de dos años correspondientes a las dos crisis de mortalidad importantes no hicimos tratamiento alguno de los valores de sus números anuales de bautismos, simplemente incorporamos sus valores a la gráfica final, mientras que para el intervalo de nueve valores (de 1701 a 1709) calculamos, por mínimos cuadrados, la mejor recta que representaba los datos que había en él. La Tabla 2 contiene los «mejores resultados» de los análisis correspondientes a 58 y 29 datos, respectivamente, para los números de bautismos del colectivo de 64 entidades de población que estamos manejando.

\section{Tabla 2}

Intervalos temporales de estabilidad poblacional de 1712 hasta 1769 (58 años) y de 1772 a 1800 (29 años). Análisis con distintos tamaños de cohortes de datos

\begin{tabular}{|l|c|c|c|c|}
\hline Número total de datos & $\mathbf{5 8}$ & $\mathbf{2 9}$ & $\mathbf{1 0 0}$ & $\mathbf{1 0 0}$ \\
\hline Número datos por cohorte & $\mathbf{7}$ & $\mathbf{1 2}$ & Tam. Vari. & $\mathbf{1 0 0}$ \\
\hline Intervalos temporales de & $1712-1725$ & $1772-1783$ & $1701-1709$ & $1701-1800$ \\
estabilidad poblacional & $1726-1732$ & $1784-1800$ & $1710-1711$ & \\
& $1733-\mathbf{1 7 7 5 3}$ & & $1712-1725$ & \\
& $1754-1760$ & & $1726-1732$ & \\
& $1761-1769$ & & $1733-1753$ & \\
& & & $1754-1760$ & \\
& & & $1761-1769$ & \\
& & & $1770-1771$ & \\
& & & $1772-1783$ & \\
& & & $1784-1800$ & \\
\hline DS \% sobre el promedio & $+4,69$ & $+2,95$ & $+4,26$ & $+6,43$ \\
\hline \% aumento población & 43,99 & 4,50 & 56,76 & 80,54 \\
\hline TBN, por mil habitantes & 37,06 & 38,32 & 37,06 & 36,40 \\
\hline
\end{tabular}


Los resultados refiejados en la Tabla 2 indican que la representación conjunta de la unión de las mejores rectas para los periodos de estabilidad, entre los años de crisis de mortalidad importantes, están dentro de la precisión del $5 \%$ exigida a priori. De cualquier modo, la mejor representación en el caso del colectivo de 1712 a 1769, es la que se obtiene analizando los datos de bautismos con cohortes de siete datos. Por su parte, los resultados (valores de DS\% sobre el promedio) recogidos en la misma Tabla 2 ponen de manifiesto que la «mejor representación» para el intervalo de 1772 a 1800, es la procedente del análisis con cohortes de doce datos. Las Figuras 8 y 9 recogen las mejores representaciones de los datos empíricos obtenidas en estos análisis.

Uniendo todas las informaciones deducidas hasta ahora, para los cinco periodos temporales en que, inicialmente, hemos dividido el Siglo XVIII en Asturias, podríamos llevar a cabo una representación general de la evolución temporal de su población, uniendo los distintos periodos hallados de estabilidad con los datos de los dos intervalos de 1712 a 1769 y de 1701 a 1709 al intervalo simplemente calculado para el periodo de 1701 a 1709 y los datos originales de los años $1710,1711,1770$ y 1771 . Los resultados obtenidos se representan en la Figura 10, en la que la línea quebrada calculada es la que creemos «representa mejor» la evolución temporal de los números anuales de bautismos. Lo hace con una desviación cuadrática media frente a los valores empíricos del $\pm 4,26 \%$ del promedio, es decir, lo hace dentro de la precisión exigida al experimento. Si se compara este valor con el procedente de la recta de tendencias, que vale un $\pm 6,43 \%$, la mejora conseguida con la última representación es evidente. La podríamos cifrar en alrededor de un $34 \%$. Los resultados de este cálculo aparecen también en la Tabla 2.

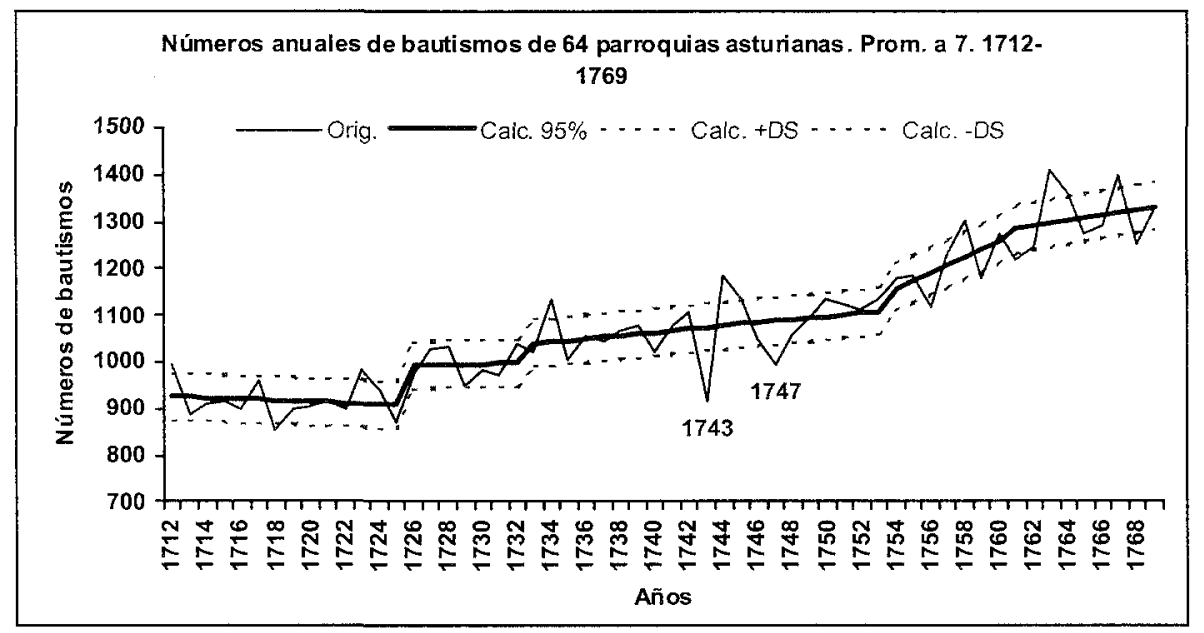

Figura 8 


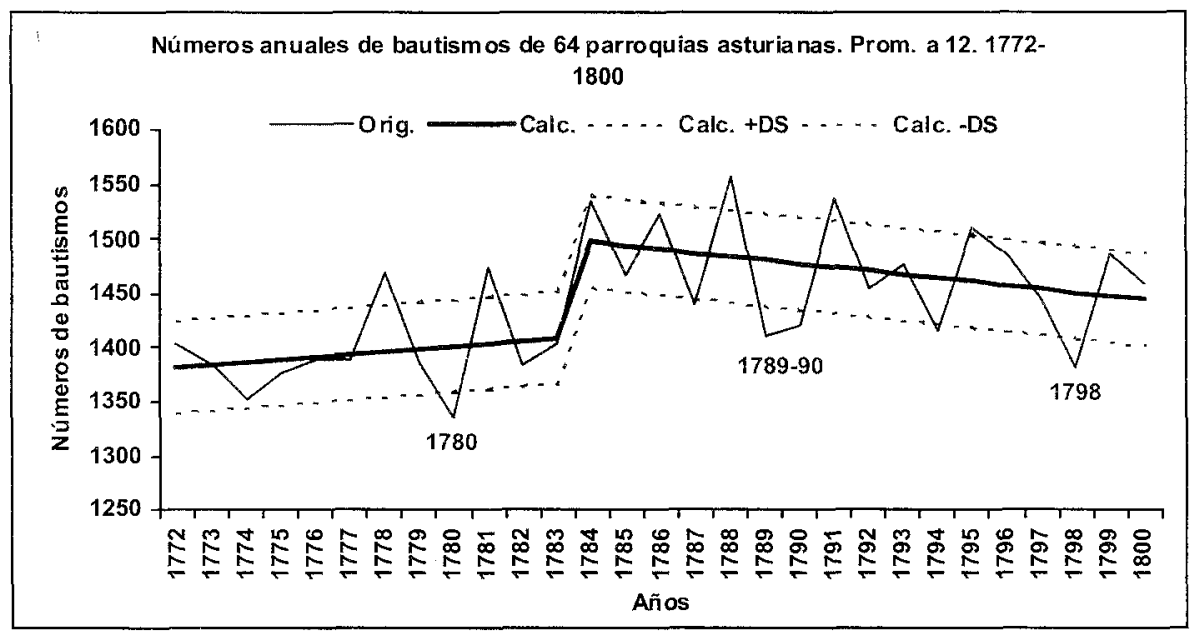

Figura 9

En la Figura 10 se recogen, además de los «descensos anormales de los números de bautismos que hemos representado en las Figuras 8 y 9», los de los años 1710-1711 y 1770-1771, así como uno en el año 1725, descenso este último que corresponde a un índice de natalidad (Figura 7) de tipo normal, pero próximo al de tipo medio. Lo cierto es que nuestro método funciona adecuadamente. Quizás es algo menos fino que el de calcular los índices de natalidad, pero frente a éste tiene la ventaja de poder suministrar, dentro de la evolución de la misma, una serie de periodos de diferentes pendientes, dentro de los que, en cada uno, la población fue evolucionando de distinta forma. La Tabla 3 contiene datos al respecto como «tantos por ciento de variación de la población» calculados, para cada intervalo estacionario entre cambios, en la suposición que, en ellos, se mantuvo constante la Tasa Bruta de Natalidad, pero en los que las cuantías y, lo que quizás es más importante, los repartos de los habitantes entre sexos (hombres y mujeres), edades y estados civiles (solteros y casados) eran diferentes, produciendo, con ello, un tasa de crecimiento estacionario diferente. En la misma tabla hemos incluido los «periodos de estabilidad poblacional», que se obtendrían en la suposición de que la Tasa Bruta de Mortalidad de Mayores se mantuviese constante y de que, por ello, la población fuese proporcional a los números de entierros de mayores cosa que, a priori, no es.

Los datos de la Tabla 3 nos permiten deducir las épocas en las que el crecimiento de la población asturiana en las zonas rurales, medido como la tasa de crecimiento anual, prácticamente se detuvo (1726 a 1732), fue negativa (1712 a 1725 y 1784 a 1800) o fue la mitad, aproximadamente, que el crecimiento promedio obtenido para todo el siglo (1772 a 1783). En contraste a ellas, hubo fases en las que fue más parecido al crecimiento promedio atribuible a todo el siglo (1733 a 1753 y 1761 a 1769) y, una, en las que se disparó hacia arriba (1754 a 1760). De las dos épocas de crecimiento 


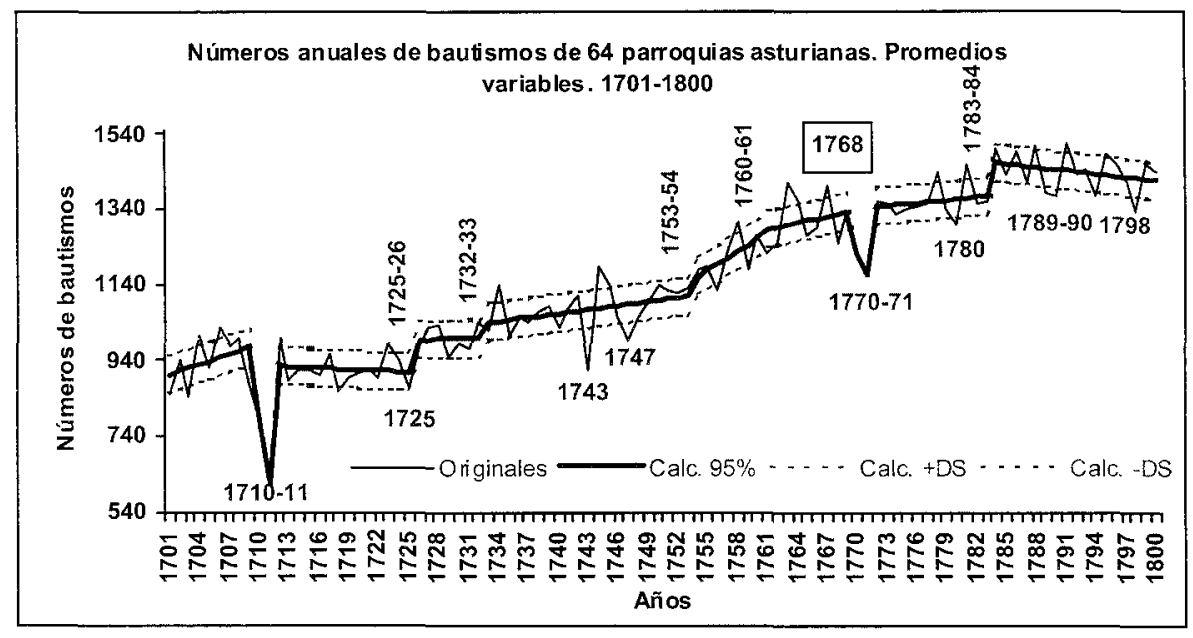

Figura 10

anual negativo, la de los primeros trece años transcurridos tras la «gran crisis de mortalidad» de 1710-1711 es perfectamente explicable, como consecuencia de las mortalidades de «no niños» (entre unos 12 y 25 años) que, casi seguramente, se produjeron en este bienio. La edad más probable de casamiento de los pobladores de Asturias se puede calcular a partir de los Censos de Aranda y Floridablanca ${ }^{23}$, resultando ser del orden de 26 a 27 años. Por el contrario, el crecimiento tras los dos años de la crisis de mortalidad de los años 1770-1771, también de tipo «gran crisis», no fue negativo, pero sí menor, que el del promedio del siglo, 2,15 por mil anual frente al 4,55 por mil. Es decir, según lo hallado, la crisis de 1770-1771 no produjo los mismos efectos, en cuanto a la evolución de la población, que la de los 1710-1711.

En la Tabla 3 se incluyen los resultados de aplicar el mismo método de comparación de cohortes sucesivas a los datos de números anuales de entierros de mayores. La mejor representación de la evolución de, en este caso, la mortalidad de mayores a lo largo del siglo aparece representado en la Figura 11, junto con la evolución temporal de los números anuales de bautismos.

Comparando entre sí las dos líneas quebradas (Calc. Ba. y Calc. En.) de la Figura 11 parecen claras todas las particularidades de las mismas. Tras el cataclismo de los años 1709 a 1711, sus secuelas parece que duraron hasta el año 1725. El hecho de que durante los 12 o 13 años posteriores a esta crisis continuase subiendo la mortalidad de mayores mientras que continuaba bajando la natalidad, revela que, muy probablemente, la «gran crisis» de comienzos del siglo fue de larga duración, quizás debida a cambios

23. Ansón Calvo, M. C. Asturias en la España de Carlos $111, \ldots$ Oviedo, 1998, p. 59 y Ansón Calvo, M. C., Asturias en 1787: Demografia,... Oviedo 1992, p. 105. 


\section{Tabla 3}

Intervalos temporales de estabilidad poblacional de 1701 hasta 1800 (100 datos) Resultados de análisis con cohortes de tamaños variables de los datos de números anuales de bautismos, entierros de mayores y matrimonios

\begin{tabular}{|l|c|c|c|c|c|c|}
\hline \multicolumn{1}{|c|}{ Tipo de dato } & Bautis & Bautis & Bautis & Ent. Mayo & Ent (M) & Ent (M) \\
\hline & Años & Crec.\% & /m año & Años & Crec.\% & /m año \\
\hline & $1701-1709$ & 8,13 & 9,82 & $1701-1709$ & 113,94 & 99,73 \\
& $1710-1711$ & & & $1710-1711$ & & \\
& $1712-1725$ & $-1,88$ & $-1,46$ & $1712-1724$ & 33,61 & 26,69 \\
Intervalos temporales & $1726-1732$ & 9,94 & 0,83 & $1725-1737$ & 13,11 & 12,12 \\
de estabilidad entre & $1733-1753$ & 11,04 & 3,21 & $1738-1769$ & 2,11 & 0,67 \\
las crisis importantes & $1754-1760$ & 13,63 & 13,86 & $1770-1771$ & & \\
& $1761-1769$ & 5,80 & 4,58 & $1772-1785$ & 9,48 & 7,58 \\
& $1770-1771$ & & & $1786-1800$ & 7,27 & $-8,57$ \\
& $1772-1783$ & 2,02 & 2,15 & & & \\
\hline Tasa Crec./Mil anual & $1784-1800$ & 2,93 & $-2,10$ & & & \\
\hline DS \% promedio & $1701-1800$ & & 4,55 & $1701-1800$ & & 8,67 \\
\hline Total crecimiento \% & & 4,26 & & & 10,97 & \\
\hline Tasas Brutas / mil & & 56,76 & & & 135,00 & \\
\hline $\mathbf{R}^{\mathbf{2}} \mathbf{N}^{\mathbf{0}}$ anuales:Años & & 37,06 & & & 13,32 & \\
\hline Intervalos entre & $1768-1787$ & 9,51 & & $1768-1787$ & 14,15 & \\
censos & $1787-1797$ & $-2,08$ & & $1787-1797$ & $-0,28$ & \\
\hline
\end{tabular}

climatológicos acompañados de una serie de malas cosechas o quizás debidos a las secuelas de la Guerra de Sucesión (1702-1713). A partir del año 1726 la población estudiada comienza una época de crecimiento muy lento quizás generado por la «crisis fuerte de mortalidad» de los años 1729 a 1731 . Desde 1732 se produce un crecimiento más fuerte hasta el año 1753, a pesar de las crisis de mortalidad, menor, media y fuerte de los años 1740, 1742-43 y 1748-49, que si bien «se notan» en algún descenso puntual de bautismos, no lo disminuyen. A partir del año $1754 \mathrm{el} \mathrm{crecimiento} \mathrm{se} \mathrm{acentúa} \mathrm{mucho}$ hasta el año 1760. Ahora bien, en el año 1761, como consecuencia de una crisis de mortalidad fuerte en los años 1761-62, el crecimiento se ralentiza un poco respecto al periodo anterior. La Gran crisis de mortalidad de los años 1770-1771, hace que dicho crecimiento todavía se ralentice más, aun teniendo en cuenta que sólo en el año 1783 hay un cierto conato de crisis de mortalidad, pero la población, que había comenzado a crecer de nuevo a partir del año 1784 , comienza un periodo de disminución que dura hasta el final del siglo debido, posiblemente, a la crisis de mortalidad «fuerte» de los años 1786-1787. 


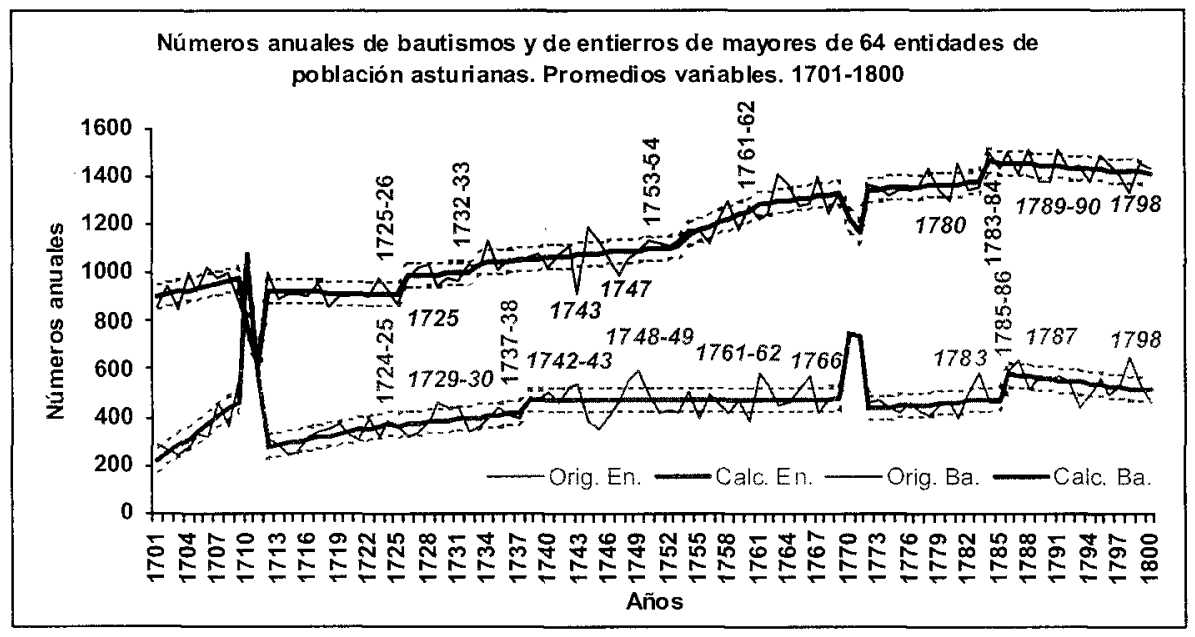

Figura 11

\section{NATURALEZA Y CAUSAS DE LAS CRISIS DETECTADAS}

Sobre algunas de las crisis aquí presentadas, hace un tiempo di ya noticias en un trabajo en el que aportaba datos documentales y bibliográficos ${ }^{24}$. En el presente estudio se tendrán en cuenta las informaciones allí recogidas y se complementaran con otras noticias y datos sobre las crisis sufridas en la Asturias del siglo XvIII, conectándolas a su vez con las que se presentaron en España en esta misma centuria.

Como hemos comentado, los datos de mortalidad nos señalan ya en la primera década del siglo una crisis fortísima, tanto que se puede considerar como la más grave de la centuria. La crisis comienza en los últimos meses del año 1709 y tiene su mayor virulencia en el bienio 1710-1711, con un claro descenso en el número de fallecidos a lo largo del año 1712. No obstante, la importancia de esta crisis no sólo debemos de constatarla en las cifras de difuntos sino también en las de bautismos habidos tras ella, pues como se refleja en la gráfica 11, el numero de bautismos o niños nacidos baja muy ostensiblemente en los años 1711-1712 como una clara consecuencia de la mayor mortalidad habida entre los años 1709-1710, mortalidad que sin duda llevó una parte importante de la población de mayores que hubiera dado lugar a generar posibles nacimientos.

En relación con esta «gran crisis» de los años 1709 a 1711 , de los datos de la Tabla 3 es posible deducir que sus efectos se tradujeron, en cuanto a la población, en la existencia de una tasa de crecimiento, entre los años 1709 y 1725 (año en que,

24. Ansón Calvo, M. C., «La Población Asturiana en el Siglo Xvill. Crisis demográficas». Historia de Asturias, Tomo III, Edad Moderna. Gijón, 1978, pp. 73-78. 
de nuevo, la población comenzó a crecer) de un $-4,41$ por mil anual (crecimiento del $-6,86 \%)$. Con estos datos y con la TBN del año 1768 , que suponemos constante, es posible calcular en habitantes lo que disminuyó la población de Asturias Rural en los años de 1709 a 1725 como consecuencia de la citada crisis de mortalidad y de este cálculo resultó la cifra de 17266 pobladores. Antonio José de Cepeda que, enviado por la Junta Central, residió esos años en Asturias, nos asegura que en este año, 1710, el número de muertos habría pasado «según cómputo de prudentes, de veinte mil» y él mismo nos dice «en los campos, en las calles y en los caminos vi y encontré muchos niños, hombres y mujeres y de todas edades y estados, muertos, sin más enfermedad que su hambre, necesidad, desnudez, y miseria $\rangle^{25}$. La cifra de 17266 habitantes que hemos encontrado es bastante coincidente con la dada por Cepeda, toda vez que no se refiere a toda Asturias Rural pues la ciudad de Oviedo no se puede considerar «rural» como el resto.

No obstante debemos señalar que la crisis de 1709-1711 fue extensiva no sólo a España sino a casi la totalidad de los países europeos. Así, la encontramos citada en trabajos de demografía belgas, alemanes y se la denomina como crisis de gran virulencia en estudios sobre la población francesa. El llamado «duro invierno europeo» de 1709, con sus gravísimas repercusiones en la producción agraria y en la ganadería, se reflejó en el elevadísimo número de difuntos registrados en los archivos de las distintas parroquias europeas. España, muy debilitada ya por la escasez de granos derivada de las malas cosechas de 1705-1706 y 1708 y por los episodios bélicos de la guerra de Sucesión, soportará la llegada de los intensísimos fríos de 1709 y las consecuencias de los mismos. Asturias, como lo demuestran los datos, no se libró de la virulencia de esta crisis y de sus consecuencias, más lesivas posiblemente debido a las características de su suelo y a su geográfico aislamiento. No debemos olvidar que Asturias era deficitaria en granos en épocas de normalidad, por lo que su situación de precariedad se agravaba en años de carestía o de crisis agrarias, obligándole a tener que comprarlos en momentos en que esta carestía había propiciado la subida de precios. Estos, dada la situación geográfica de Asturias y las dificultades viarias para el transporte, se elevaban muy ostensiblemente desde el lugar de compra hasta su destino, por lo que la población asturiana sufría doblemente el alza de precios en los productos básicos, esas alzas que Hamilton recoge para la España del siglo XVIII.

La panorámica casi dramática que presenta Cepeda sobre Asturias no es la única. Feijoo, que por estos años ya ejercía su magisterio en Oviedo, nos relata en su «Teatro Crítico» cómo «caían los hombres por las calles, no cabían los cadáveres en las sepulturas de las iglesias y fue preciso sepultarles en el campo». En esta línea estará la petición de «alguna limosna que en junio del año 1710 hará el encargado de las sepulturas al Ayuntamiento de Oviedo», porque, como él mismo señala, su trabajo ha aumentado ostensiblemente ya que «desde la epidemia reinante ha dado ya enterramiento a 600 pobres». En el mismo sentido de quejas y abatimiento, debido a las hambres y calami-

25. ANES, G., Historia de Asturias, Edad Moderna H... Gijón, 1977, p. 15. 
dades soportadas, se pronunciarán otras corporaciones municipales de los más importantes Ayuntamientos asturianos. Así, por ejemplo, los representantes del Ayuntamiento de Avilés acuerdan desalojar la cárcel para poder meter en ella «tanto hombre que andaba sin abrigo ni alimentos». Prueba evidente de la grave situación económica en 1710 es el hecho, citado por Garralda ${ }^{26}$, de que en la Adoración de la Santa Cena del Viernes Santo «se recaudaron tan sólo 8 reales, y con 20 reales se compraba tan sólo un cántaro de vino». Muy mal debía de estar la economía de los avilesinos para contribuir con tan pequeña aportación a la Iglesia en un día destacadamente señalado.

A los intensos fríos y a la durísima crisis agraria se sumaron en toda España y en otras partes de Europa una serie de crisis epidémicas, entre ellas tifus, que Ilevaron también muchas vidas. No sabemos cómo pudieron afectar éstas nuevas calamidades a Asturias, pero lo que si podemos asegurar es que en 1711 la situación para el Principado seguía siendo casi crítica. Así se desprende, por ejemplo, de las quejas presentadas por los vecinos de Oviedo a su Ayuntamiento, que dicen han «levantado» cuarenta pobres muertos dispersos en casas y calles de la ciudad «porque no cabían más en la capilla de San Cipriano y piden la bendición de un nuevo lugar para sepelirlos». Esta queja será reiterativa en otras situaciones similares, pues casi un siglo después, el año 1804 se señala de nuevo que «no caben los cadáveres en San Cipriano» y el año 1813 se habla de trasladar el cementerio ovetense al «Picón». Es decir, el problema sobre la necesidad de un nuevo cementerio no tuvo fácil ni rápida solución. Volviendo al tema que nos ocupa, realmente, aunque las noticias sobre la situación crítica de los años 1709-1711 proceden de la capital del Principado, no tenemos porqué pensar que esta dramática situación se diera tan sólo en ella, sino que parece era la real en todo Asturias en estos años y deducir que mala climatología, crisis agrarias y enfermedades de distintos tipos afectaron seriamente a la tierra y al pueblo asturiano, ocasionando elevadas mortandades y dejando extenuada su economía y su demografía.

Tras casi una treintena de años de escasos contratiempos biológicos, la población asturiana sufrirá de nuevo una serie sucesiva de crisis de mortalidad en los años 1735$36,1742-1743$ y $1747-1749$. Nuestros datos extraídos de los archivos parroquiales las demuestran, pero también algunos contemporáneos a las mismas dan noticias sobre los ataques infecciosos que sufrió la población. Así, es un hecho afortunado el que para el estudio de las crisis en esta época Asturias tenga un testigo de excepcional importancia. Me refiero a Gaspar Casal ${ }^{27}$ que, aunque ejerció como médico de la ciudad de Oviedo, conoció y estudio también las enfermedades sufridas en distintas partes de Asturias y, debido a ello, escribió una obra de capital interés, «Historia Natural y médica del Principado de Asturias». En ella expone y explica magistralmente las enfermedades que trató y los remedios que aplicó para su curación. A este respecto, parece curioso constatar, como ejemplo de que algunos procesos epidémicos pueden ser mucho más

26. Garral.DA, A., Avilés, su fe y sus obras. Avilés, 1970.

27. Casal, G., Historia Natural y Médica del Principado de Asturias (1762). Edición Facsímil. Oviedo, 1959 . 
virulentos en la ciudad que en el campo, el hecho de que Casal al hablar sobre las enfermedades y crisis sufridas por la población asturiana cita un fuerte proceso epidémico que tuvo su desarrollo entre el otoño de 1735 y parte del invierno de 1736 y que, según él, dio origen a «muchas fiebres ardientes, petequiales, malignas y peri-neumónicas», que le obligaron a practicar numerosas sangrías. Esta crisis, que debió de ser de origen variólico, a juzgar por algunas noticia que recogen las Actas del Ayuntamiento oveten$\mathrm{se}^{28}$, parece que tuvo su principal foco en Oviedo-ciudad, pues se refleja en la cuantía de fallecidos en el colectivo ciudadano, pero no destaca en las cifras del colectivo rural.

La leve crisis que abarca los años 1742-43, aunque en el caso asturiano se circunscribió a este bienio, todo indica que el hambre y un proceso epidémico fueron las causas principales. En otras zonas españolas y europeas tuvo una mayor extensión temporal y una intensidad variable. Así, por ejemplo, Lachiver la cita como excepcionalmente grave para Meulan (Francia), Perrenoud en su trabajo sobre Géneve (Suiza) y Francois la recoge en sus estudios sobre distintas ciudades alemanas, como causada por hambre y disentería ${ }^{29}$.

De mayor intensidad fue para Asturias la crisis sufrida entre los años 1747-1749, crisis de la que queda constancia no sólo en los datos extraídos de actas sacramentales de archivos parroquiales, sino también de documentos de otra tipología (Libros de Acuerdos, Libros de Actas de los Ayuntamientos etc.) y noticias puntuales debidas a la pluma de los contemporáneos, que nos señalan la tipología de la crisis y su virulencia. Así, de nuevo tenemos que volver a Casal que nos dice: «el año 1747 comenzó con ictericias en marzo y el estío trajo fortísimas nieblas, que produjeron catarros y viruela con mucha malicia y así fueron muchos los niños y muchachos que se murieron en Oviedo». La situación climática, como es lógico, no se circunscribió a la capital, sino a toda Asturias y también la epidémica. El mismo Casal lo certifica al decir que «el 20 de diciembre del mismo año ya había comenzado la epidemia en Gijón» y los datos numéricos de difuntos de la zona rural estudiada constatan también su extensión.

En el Libro de Acuerdos del Ayuntamiento de Oviedo del año $1746^{30}$ se recoge que, con fecha 10 de abril, estando reunidos en la Casa del Ayuntamiento el Justicia y Regimiento se acuerda «Que en consideración a las enfermedades y mal temporal que se está experimentando se hagan rogativas a los patronos Santa Eulalia de Mérida y a San Roque para el martes, día 12». Es decir, cuando los medios terrenales eran insuficientes para paliar la situación se recurrió, una vez mas, a la mediación del poder divino, con la intervención de los santos protectores de la ciudad. Pero, a pesar de todo, la situación climática no debió de tornarse halagüeña para el campo y sus cultivos, porque

28. Ansón Calvo, M. C., «La Población Asturiana en el Siglo XVIIl...». Historia de Asturias, Tomo III, Edad Moderna. Gijón, 1978, pp. 75.

29. Annales de Demográphie Historique, Año, 1978.

30. A(rchivo) H(istórico) M(unicipal) de Oviedo. Varios Libros de Acuerdos. 1705 a 1801 y Respuestas Generales del Catastro del Marques de la Ensenada. 
unos meses después, el 28 de septiembre, nuevamente la corporación municipal nos habla de «la suma carestía de granos, así de pan como de maíz que se ha experimentado en este presente año, y como se ha acrecentado el precio de los que se están vendiendo en el mercado de la plaza pública de la ciudad» y señalando la precaria situación de los más desprotegidos decidirá que «ante el aprieto que sufren los pobres se considera necesario que la ciudad compre grano barato en Castilla y lo traiga y lo venda a precio de coste ${ }^{31}$. Cinco meses mas tarde, ya el 29 de febrero de 1747 la misma Corporación trata el tema de la carestía y de la necesaria provisión de granos del exterior, al recordar que «hace tres meses se había dado comisión a D. Alonso Benito y a D. José Requejo para que condujesen trigo de Castilla por la mucha esterilidad de granos del año presente» y todavía no había llegado. La triste realidad es que «la salud» del erario del más importante municipio asturiano estaba muy mal, tanto que tuvo que pedir al Cabildo de la ciudad 75.000 reales de censo ${ }^{32}$. A este respecto no se debe de minusvalorar, ni mucho menos olvidar, la situación geográfica de aislamiento de Asturias y las consecuencias derivadas de la misma, en especial las repercusiones que cualquier crisis económica o agraria tenía en la población asturiana, si tenemos en cuenta que para esta región hasta épocas muy próximas a nuestros días la naturaleza de la red viaria y los medios de transporte influían muy fuertemente en el mercado interior, por los altos costes de los desplazamientos. Baste recordar que, según mis estudios, en situaciones «normales», de la colindante provincia de León a Asturias las tarifas de transporte representaban a veces hasta el 50 por 100 o más del precio de origen en artículos tan básicos como el trigo. Situación muy similar se daba en otros artículos, también básicos para la época, como los vinos, cuya provisión resultaba más barata si procedía de Cataluña que de tierras de Castilla, por el menor coste del transporte por vía marítima. Ir de Asturias a las provincias vinícolas del Duero o a proveerse de los vinos vallisoletanos de Rueda (muy apreciados y consumidos por los asturianos), era una operación carísima, pues debido a la casi inexistencia de carreteras o vías transitables, había que hacer el transporte de la mercancía a lomos de animales, lo que derivaba en un aumento de 80 reales la arroba porque, a pesar de que León y Oviedo distaban solo 20 leguas, el precio del transporte era de 5 a 6 reales la fanega. Estos datos conducen a pensar que si esta era la situación en tiempos de normalidad, en momentos de crisis agrarias o de otro tipo el panorama podía llegar a ser dramático. La realidad es que las malas cosechas y el elevado precio de los alimentos repercutió seriamente en la población asturiana que quedó debilitada y poco preparada para poder soportar las epidemias que iba a sufrir subsiguientemente, pues Casal nos dice que en los años 1747-1749 todo el Principado sufrió epidemias continuas de catarros, ictericias, viruela y fiebres malignas, «que se contagiaban como la peste» y que en algunos pueblos, señalándonos pues la zona rural, llevaron hasta un tercio de la población. Nuestros datos no parecen señalar que fuese tan grave pero, sin duda, lo fue a los ojos de Casal, nuestro destacado sanitario contem-

31. Ibid. Año, 1746, Fol. 36 y 103.

32. Ibid. Año, 1747, Fol. 12. 
poráneo de la misma. También, de nuevo Feijoo destaca la penuria que sufrió Asturias en esos años y cómo el mismo contribuyó económicamente para aliviar el hambre y la miseria de los más necesitados. Todo parece conducirnos a reconocer que hubo seria carestía de alimentos básicos y hambre, derivando después en epidemias y mortandades. Los datos y las noticias lo confirman. Por otra parte, hay que hacer constar que la situación asturiana se agravó porque la provincia vecina, León, también sufrió malas cosechas y crisis en estos años, como hemos comprobado en las actas de defunciones parroquiales leonesas y en las reiteradas noticias recogidas en los Libros de Acuerdos del Ayuntamiento de León sobre «la falta de trigo en la ciudad» y también repetidas alusiones al «excesivo número de pobres que mueren en ella» ${ }^{33}$. Así pues, debemos señalar la existencia de una serie de crisis entre los años 1732 a 1750. Sin embargo, de las noticias cualitativas sobre ellas no se puede deducir su intensidad. Sin embargo, los datos de la Tabla 3 si que lo permiten, pues nos llevan a la conclusión que «el estado de la población» era tal que en este tiempo disminuyó en más de un 29 por ciento la tasa promedio de crecimiento de Asturias durante el siglo XVIII. Así, ésta entre los años 1732 y 1753 fue de 3,21 por mil anual, frente al 4,55 por mil anual que, como promedio, se obtiene para de todo el periodo.

Resumiendo los hallazgos sobre la existencia de crisis de mortalidad en Asturias basados en documentos históricos o bibliográficos de Casal, Cepeda, Feijoo, Actas del Ayuntamiento de Oviedo, Censo de Aranda $^{34}$, en que los autores describen diversas épocas de penurias alimenticias por malas cosechas y, o, epidemias que azotaron Asturias, en especial Oviedo, en los años que fueron desde 1735 a 1748, podemos confirmar las disminuciones de bautismos halladas (Figura 11) para los años 1743 y 1747. Las descripciones que hacen los escritores de la época podrían dar lugar a una sobrevaloración de los efectos de tales crisis en el crecimiento de la población, cosa que los datos de la Tabla 3 ponen en su lugar. En ésta, los valores de los crecimientos sostenidos de los bautismos durante los periodos de estabilidad en el crecimiento, dados en tantos por mil, indican que durante el periodo de 1733 a 1753, entre los que se incluye la aparición de las crisis de 1735-36 y de 1747-50 descritas por Casal ${ }^{35}$, la población de la Asturias rural creció con un crecimiento sostenido del 3,21 por mil anual. Entre 1701 y 1800 , a pesar de las diferentes crisis sufridas, la población de Asturias creció, en promedio, al 4,55 por mil anual (Tabla 3 ). Es decir, durante los años de las citadas penurias, pese a todo, según la evolución de sus bautismos, la población de Asturias creció, algo menos que el promedio, pero creció. Tras estos años, entre 1754 y 1760 , aparece una corta etapa de crecimiento espectacular de los bautismos (13,86 por mil anual), seguida de otra, también corta (de 1761 a 1769), con crecimientos más parecidos al crecimiento promedio (4,58 por mil anual).

33. A(rchivo) H(istórico) M(unicipal) de León. Varios Libros de Actas, o Acuerdos Capitulares. 1708-1772. 34. Ansón Calvo, M. C., «La Población Asturiana en el Siglo XVIII...». Historia de Asturias, Tomo HI, Edad Moderna. Gijón, 1978, pp. 73-78.

35. CASAL, G., Historia Natural y Médica del Principado de Asturias (1762)... 
Según lo expuesto, todos nuestros datos nos llevan a concluir que Asturias sufrió también la crisis generalizada española de los años 1738-1742. Barreiro y Saavedra ${ }^{36}$, la señalan como crisis sufrida en Galicia y Pérez Moreda ${ }^{37}$ en la España interior, en especial, con alta mortalidad entre los «párvulos». Sanzo Fernánde $z^{38}$ en las páginas iniciales de su trabajo sobre Asturias, hace una recopilación de las crisis demográficas del Antiguo Régimen y, en ella, refiere como crisis generales las de los periodos 1698-1699, 1709-1710 y 1765-1769. Esta última, no aparece como una crisis muy importante con nuestro tratamiento. De las gráficas de la autora no es posible deducir los valores de los números anuales de bautismos y entierros de mayores que utiliza para acumularlos y establecer su evolución con el tiempo a lo largo del siglo XVIII, dejándolos en condiciones de aplicarles la metodología que hemos desarrollado, por lo que no hemos podido hacerlo. Tan sólo puedo aportar, como ya expuse en una publicación anterior ${ }^{39}$, que según nuestros datos la crisis de subsistencias de los años 1763 a 1765 no tuvo una excesiva virulencia en la zona rural asturiana. Pérez Moreda valora la crisis que rodeó los años 1762 a 1765 como «la crisis más extendida e intensa de todo el siglo XVIII» $\gg^{40}$, apuntando como una de las principales causas el descenso de los rendimientos medios de la agricultura, debidos prioritariamente a sequías continuas, que llevaron a la población a una situación tan crítica que el Gobierno decidió imponer medidas liberalizadoras en el comercio de granos por la Pragmática del 11 de julio de 1765, a pesar de las cuales no pudo evitar los motines que «contra los elevados precios del pan y contra Esquilache» tendrían lugar en la primavera de 1766 en Madrid, repercutiendo también en otros lugares de España. Aún con todas estas noticias, en el caso asturiano, según nuestros datos, la crisis no parece que tuvo la virulencia que se describe para otros lugares de España.

De lo expuesto parece que puede hacerse una observación interesante, reflejada en la Figura 11 y es que la evolución temporal de la mortalidad «de fondo» desde el año 1712 al 1737 es creciente y entre los años 1738 y 1769 se «detiene», por decirlo de algún modo, ya que, prácticamente, se mantiene casi constante en un valor de 0,67 por mil anual, lo que propicia el crecimiento sostenido de los bautizos, crecimiento que al menos en el periodo de 1754 a 1760 se convierte en espectacular $(13,86$ por mil anual) y que va seguido de otro entre los años 1761 y 1769 (4,58 por mil anual), que podríamos calificar como más normal, y que quizá se deba a la mortalidad infantil, de

36. Barreiro Mallon, B., La jurisdicción de Xallas a lo largo del siglo XVIII. Población. Sociedady Economia. Santiago de Compostela, 1973, p. 222 y SAAVEDRA, P. Economia rural antigua en la montaña lucense. El Concejo de Burón. Santiago de Compostela, 1979, p. 28.

37. PEREZ MOREDA, V., Las crisis de mortalidad en la España interior. Madrid, 1980, pp. 335-336.

38. SANZO FERNÁNDEZ, C. M., «La población de Asturias en los siglos XVIr a XIX: Los Registros Parroquiales». Capitulo IV de: La economia española al final del Antiguo Régimen. I. Agricultura. Madrid. 1982, pp. $26 !-343$.

39. Ansón Cnlvo, M. C., «La Población Asturiana en el Siglo xvill...». Historia de Asturias, Tomo HI, Edad Moderna. Gijón, 1978, pp. 76.

40. PEREz MOREDA, V., Las crisis de mortalidad en la España interior..., pp. 363-369. 
la que no tenemos datos ni noticias que ayuden a valorarla para el caso asturiano, pero que se conoce fue elevada en distintos lugares de la Castilla interior en los veranos de 1763 y $1765^{41}$.

Para la zona asturiana la segunda crisis de la centuria, en razón del elevado número de entierros registrados, fue la que abarcó los años 1770-1771. La mortalidad fue tan elevada que podríamos calificarla, según la clasificación de Dupaquier, de «gran crisis». De esta crisis, de la que ya di las primeras primicias en $1978^{42}$ hay testimonios documentales y numéricos muy elocuentes para el Principado y también noticias que la señalan como muy virulenta en otras partes de la España norteña, como en Xallas (Galicia), donde según Barreiro las defunciones se multiplicaron por siete ${ }^{43}$. El origen de esta fortísima crisis vino dado por las malas cosechas de los años 1768,1769 y 1770 que en Asturias motivaron la duplicidad de los precios en alimentos tan básicos como la escanda, que en estos años pasó de 4 a 7,5 reales, el trigo de 3 a 6,20 reales, el maíz de 3 a 6,20 reales el copín, y las fabes que, en distintos documentos, se denominan «principal alimento de los pobres», «en el año 1770 hubo tal escasez que llegó a valer la fanega 72 reales», según se recoge en los Libros de Acuerdos del Ayuntamiento de Oviedo de estos años. La crisis se refleja en el número de difuntos contabilizados en el colectivo rural estudiado, como también en el numero de entierros celebrados en las parroquias de la capital de la región y también constatamos su importancia a través del vaciado del numero de niños que ingresaron en estos años en la institución benéfica asturiana del Hospicio ${ }^{44}$. Dado que en ésta, desde su fundación en 1752, se hacía un registro o acta individualizada de los niños que ingresaban, hemos podido contabilizar y constatar que el número de ingresos se dispara desde el año 1769 , año en que pasa de 160 ingresos promedio anual a 310 , hallándose una máxima espectacular en los años que siguieron a la fortísima crisis de 1770, llegando entre los años 1770 a 1773 a duplicarse el numero de niños ingresados. Este aumento, casi coincidente con el reflejado en el número de defunciones contabilizadas, alcanza una cota no repetible en el siglo, siguiéndole, además, una caída de 42 por ciento en el número de eventos posteriores al año 1774, año en el que la institución benéfica recibe una media regular casi continua de 170 por año, si exceptuamos la subida registrada en el año 1798, coincidente con la fecha de la última crisis del siglo. Por otra parte, en cuanto a la numerosa recogida de niños en el Hospicio asturiano, es interesante exponer que la institución benéfica no sólo acogía a niños expósitos e ilegítimos sino también a niños pobres, a quienes sus padres dejaban allí por no tener lo imprescindible para alimentarlos, como queda recogido en distintas actas o registros de entrada. Esta doble motivación (exposición y pobreza) como vía de entrada en la institución, hizo que hubiera también una doble vía

\section{Ibid. p. 365 .}

42. Ansón CAlvo, M. C., «La Población Asturiana en el Siglo XVII...». Historia de Asturias, Tomo III, Edad Moderna..., pp. 76.

43. BARreiro Mallon, B., La jurisdicción de Xallas a lo largo del.. Santiago de Compostela, 1973.

44. Ansón Calvo, M. C., «La Población Asturiana en el Siglo XVII...». Op. cit., p. 76. 
de registro y, así, los niños expuestos o hallados quedaban registrados en los llamados Libros de Expósitos y los que no eran abandonados ni expuestos, sino llevados por sus padres o familiares por la imposibilidad de alimentarlos, en los llamados Libros de Pobres. Esto me condujo a pensar que si la aportación de niños abandonados se «disparó» en los años de crisis, como ya hemos señalado, también los años cataclismicos se manifestarían en el aumento de pobres que pedían ayuda en el centro benéfico asturiano. Tal suposición se confirmó al hacer los recuentos anuales de ingresos, pues entre los años 1758-1767 se registraron una media de 25 entradas anuales, el año 1769 contabilizamos 54 y el año 1770 la cifra asciende bruscamente hasta ser 78 los niños pobres recogidos. Es decir, en tres años (1768-1770) la cifra de ingresos se multiplicó por tres, con un pico altísimo en el año 1770. Es importante señalar que, además, la crisis debió de ser tan grave que la Institución recogió en estos años varios niños y adolescentes hermanos que habían quedado huérfanos y con frecuencia encontramos registrados viudas con todos su hijos, que aducen el tener que entrar «por no tener nada con que alimentarse».

A través de lo expuesto podemos aseverar que la crisis que rodeó al año 1770 se constata en toda la documentación consultada y que la falta de alimentos básicos y el hambre se sufrió en los distintos estratos de la sociedad y en la población de distintas edades, lo que generó el que muchos niños murieran y otros quedaran huérfanos o con familias paupérrimas, incapaces de poder alimentarles Una vez más la dura orografia de la tierra asturiana nos hará recordar las dificultades que la cadena montañosa separadora de la meseta castellana presentaba para el transporte de granos y el precio que éstos llegaban a alcanzar en épocas de carestía, en especial, si como ocurrió en éstos años, la crisis se extendía a la región vecina, León, que según mis investigaciones sufrió en 1770 su tercera peor crisis del siglo. Así pues, distintas variables coincidentes nos llevan a deducir la dureza de esta crisis, que en el caso asturiano puede considerarse la segunda más agresiva del siglo XVIII. Para terminar, como dato «curioso» dentro de la situación gravísima en que se encontraba la sociedad asturiana, parece interesante presentar la siguiente noticia, recogida en los Libros de Acuerdos del Ayuntamiento ovetense, con fecha 17 de octubre de 1770 . El empresario de operas italianas Nicolás Settano pidió permiso a la corporación municipal para representar varias operas en la ciudad, pero ésta se lo denegó aduciendo que la negativa era debida a «las muchas calamidades y escaseces que estaba padeciendo». Así pues, el panorama no podía ser más sombrío para pueblo e instituciones.

Entre los años 1783 y 1790 todavía sufrirá la población asturiana algunas crisis, pero éstas pueden considerarse de pequeña entidad, aunque con diferente grado de intensidad entre los colectivos de Oviedo-ciudad y de la Asturias rural. La crisis de 1783-84 fue leve y, aunque no encontramos propiamente definida su tipología, hay frecuentes alusiones y medidas sanitarias que nos señalan que hubo contagio y epidemia ${ }^{45}$. Posiblemente fue una crisis debida al paludismo y a brotes de tercianas y viruelas, cala-

45. A(rchivo) H(istórico) M(unicipal) de Oviedo. Libros de Acuerdos. 1783. Leg. 168. 
midades que en estos años también sufrió la población de otros lugares de España. Más duros fueron los últimos años del siglo, con una serie de pequeñas crisis, entre la que hay que destacar las de los años 1786 a 1789. En el bienio 1786-87 toda España sufrió de nuevo fuertes epidemias de viruelas y de tercianas y la situación se vio agravada durante unos años por las calamitosas cosechas habidas no sólo en España sino en distintas partes de Europa en el bienio 1789-1790. En el caso español la panorámica fue más dramática por las dificultades del abastecimiento exterior, debido a nuestra guerra con Francia, tanto que el Gobierno tuvo que tomar serias medidas contra todo abuso o monopolio de granos y proveer de éstos a los Positos, medidas que paliaron en parte, sólo en parte, la situación casi límite a la que había llegado la población y de la que no lograra sobreponerse debido a las nuevas malas cosechas de 1792-1793. Aun con todo ello, debemos señalar que estas ultimas crisis, en especial aquellas que tuvieron como causa principal la carestía de alimentos, a juzgar por las cifras de difuntos obtenidas, tuvieron mayor repercusión en la ciudad que en el campo, debido posiblemente a que la población rural tenía su propios medios de alimentación y era más autárquica que la población urbana. Desde luego lo que no puede dudarse es que en la crisis que soportó el Principado en los años 1789-1790, además de tener mucho peso la epidemia de tercianas y viruelas sufrida por su población, fue una crisis debida a la carestía de alimentos. De lo recogido en los Libros de Acuerdos de algunos Ayuntamientos se deduce que la crisis afectó a núcleos grandes y pequeños, pues se reiteran las quejas por la carencia de granos y principalmente de maíz, así como también se recogen noticias sobre el mayor número de niños abandonados. Así, por ejemplo el 28 de mayo de 1789 «dada la escasez de maíz» se reúne el Ayuntamiento de Avilés para tratar sobre la retención de granos de maíz, vendidos por Nicolás Menéndez al abad de Covadonga para alimentar a los soldados que estaban haciendo la Basílica y unos días después, 30 de mayo, vuelve a reunirse «porque continua la difícil situación de carestía de granos», a la vez que se trata la situación del concejo de Corvera, también afectada por la escase $z^{46}$. Tampoco la despedida del siglo fue halagüeña para España y Asturias, que sufrirá de nuevo unos años de carestia por las malas cosechas y de alta mortandad.

De lo anterior podemos resumir que en las crisis señaladas, dando prioridad a la de 1709-1710, le sigue en importancia la crisis de mortalidad de los años 1770-1771, crisis que ningún autor había mencionado para Asturias antes de $1978^{47}$, y que motivó que el crecimiento de la población del Principado disminuyese fuertemente, ya que pasó a ser del 1,81 por mil en promedio entre 1772 y 1800 , frente al 4,58 por mil del periodo anterior a la crisis (1761 a 1769). Este crecimiento del 1,81 por mil se produce con dos periodos distintos, uno de crecimiento y otro de disminución. Crece un 2,15 por mil anual entre los años 1772 y 1783 y disminuye un 2,10 por mil anual entre los años 1784 y 1800 . El «bajo crecimiento» en el primer periodo nombrado es, sin duda, una consecuencia de la crisis de mortalidad de los años 1770-1771, pero la disminu-

46. A(rchivo) H(istórico) M(unicipal) de Oviedo. Libros de Actuerdos. 1789.

47. Ansón Cruvo, M. C., «La Población Asturiana en el Siglo Xvili...». Op. cit., p. 77. 
ción durante el periodo de 1784 a 1800 no parece que se deba, fundamentalmente, a las pequeñas crisis de mortalidad de los años 1789-1790 y 1798. Posiblemente la «amplía difusión epidémica, sobre todo del paludismo, tercianas y viruelas de los años 80 , junto con los problemas de subsistencias de $\operatorname{los} 90^{48}$ pudo alcanzar Asturias y generar la disminución observada del crecimiento anual de los bautismos» (Tabla 3). Sin embargo, personalmente creo, dado los pequeños valores de los aumentos de los números anuales de los entierros que se observan en esos años, que en lo encontrado, muy posiblemente, influyó de forma destacada la inestabilidad política que, tras la muerte de Carlos III (1788), acompañó el reinado de Carlos IV. Sus vacilaciones diplomáticas, que llevan a España a participar en varias guerras cambiando de bando, contra la Revolución primero (guerra de 1793 a 1795) y aliada con el Directorio después (guerra contra Inglaterra entre 1797 a 1891), unidas a las noticias de lo que sucedía en Francia tras la implantación del Gobierno Republicano (1789) y a los efectos de la contracción del comercio con Europa, fueron determinantes para generar lo encontrado. Este mismo argumento se podría emplear para explicar el hecho que he reseñado en una publicación sobre la emigración asturiana a finales del siglo XVIII ${ }^{49}$, en el que utilizando datos de los Censos de Aranda, Floridablanca y Godoy, encontré que, la emigración exterior disminuyó del año 1768 al año 1797. La disminución de nacimientos (población) desde el año 1784 a 1800 es paralela a la disminución de la emigración de los asturianos al exterior, que revelan los datos de los censos de finales del Siglo XVIII (Floridablanca y Godoy).

En cierta medida, se puede contrastar también algunos de los resultados hallados con los datos de los censos de población que a finales del siglo XVIII se hicieron en España y, como es lógico, en Asturias (Censo llamado de Aranda de 1768, de Floridablanca de 1787 y de Larruga-Godoy de 1797). Entre los años 1787 (año del Censo de Floridablanca) y 1797 (año del Censo de Godoy) los bautismos de la Asturias Rural disminuyen en un 2,08 por ciento. Esta disminución, según el argumento utilizado de que la tasa de natalidad de Asturias se conservó constante durante el siglo XVIII, significaría una disminución pareja de la población. Sin embargo, las cifras totales de población de los Censos de Floridablanca (corregido de ocultaciones) y Godoy (359.031 y 364.238 habitantes, respectivamente), reflejan un crecimiento poblacional en los nueve años transcurridos del 1,45 por ciento, valor pequeño pero que no concuerda bien con la disminución antes indicada. Curiosamente sin embargo, el aumento que revelan los Censos de población de los años 1787 y 1797 , va acompañado por un aumento del número de parroquias en Asturias entre ambas fechas, 688 en 1787 y 782 en 1797. El aumento de 94 parroquias en diez años es, sin embargo, un número poco creíble, pues significa un crecimiento del 13,66 por ciento en el número de parroquias $y$, por el contrario, este crecimiento va acompañado de una disminución apreciable del

48. PÉRez MOREDA, V., Las crisis de mortalidad en la España interior..., pp. 366-370.

49. ANSÓN CAlvo, M. C., 1993. «Movimientos migratorios en Asturias desde 1768 a 1857». Actas de la I Conferencia Europea de la Comisión Internacional de Demografia Histórica, V. II, pp. 457-474. Santiago de Compostela, 1993, p. 471. 
tamaño medio de las mismas, que pasa de 521,85 feligreses a 465,78 . Será necesario investigar más profundamente el «contenido» del Censo de 1797 para Asturias, pues parece lo más lógico que se recogieran en él entidades de población que hasta treinta años más tarde no se incluyeron administrativamente en el Principado. Me refiero a los concejos del llamado «Bastón de Laredo», los dos concejos de Peñamellera y el de Ribadeva que, en el Censo de 1787, estaban incluidos en la hoja de Burgos. Por su parte, entre los años 1768 y 1787 , los números anuales de bautismos de la Asturias Rural que estamos estudiando crecen en un 9,51 por ciento, valor mucho mayor que el que hemos obtenido cotejando los censos de 1768 y 1787 que resulta ser del 4,82\%.

Los datos parroquiales de bautismos, que se recogieron de forma mucho más sistemática que los de entierros, dada la importancia del sacramento del bautismo, permiten pues determinar la influencia de las crisis de mortalidad sobre la evolución de la población, ya que, la «muerte anómala en un momento determinado por una causa externa de los mayores casados» es la que modula en los años siguientes los bautismos que se van a producir en la población que los genera. En este sentido, creo que los análisis de la evolución temporal de los números anuales de bautismos del colectivo objeto de estudio, es el que, fundamentalmente, proporcionará informaciones cuantitativas sobre «la mayor parte de las características, temporales y de intensidad» de las crisis que, en un tiempo determinado, le afectaron. Coadyuva a potenciar el valor de los datos seriados de bautismos como base para analizar el papel de las crisis de mortalidad en la determinación de la evolución de la cuantía poblacional de un colectivo durante los siglos XVII y XVIII, el que, hasta más de un siglo después, no se ponen en marcha en forma generalizada métodos de control de la natalidad, por lo que, ésta, dependió fundamentalmente, de la esperanza de vida de las mujeres que, en España, era de 28 años hacia el final del siglo XVIII ${ }^{50}$ y no superó los 35 años hasta el año 1900 (Informe Gaur, 1975: 70-75). Además, la lactancia materna duraba por lo general alrededor de dos años, por lo que también fueron prácticamente constantes los intervalos entre nacimientos sucesivos. En esta situación, no es de extrañar, como ya hemos apuntado, que algunos demógrafos opinen que «la tasa bruta de natalidad no cambió desde el siglo XVII hasta hace escasos años $\rangle^{51}$.

Para terminar, conviene señalar que la elección del siglo XVIII como época de estudio obedeció, principalmente, a dos razones. la primera es la disponibilidad de los valores de las poblaciones de todas las parroquias de Asturias en el año $1768^{52}$ y la segunda es que es este siglo en el que, de forma sistemática y casi sin lagunas, se encuentran series de actas de bautismos, entierros y matrimonios en un número suficientemente elevado de parroquias. Por ello, creemos es a priori un laboratorio adecuado para poner a prueba el método de análisis de «sucesiones de datos», método

50. LIVI BACCl. - «Fertility and nuptial changes in Spain from the late 18 th to the early 20 th centuries». - Population Siudies, 22. 1970, p. 399.

51. Cox, P. R. Demography. Cambridge, 1970, p. 387 y sig.

52. Ansón Cal.vo, M. C. El Censo de Aranda... Oviedo, 1997. 
que utilizaré para determinar las localizaciones y cuantías de las crisis de mortalidad. En principio me he resistido a llamar series a los conjuntos sucesivos, con periodicidad de un año, de los datos de números anuales de bautismos, o de entierros de mayores, de una parroquia, pues la conjunción de acciones de los tres tipos de sucesos, que confluyen en la determinación del valor de cada uno, no tiene, a priori, una regla determinada de actuación (o sí la tiene no es conocida). De hecho, si lo fuera, no tendríamos que llevar a cabo análisis de los datos empíricos.

\section{CONCLUSIONES}

De todo el trabajo anteriormente descrito emergen una serie de conclusiones, algunas de tipo general y, otras de tipo más particular en relación con el problema de «las crisis de mortalidad» que la población asturiana sufrió a lo largo del siglo XVIII.

El análisis de los datos seriados de entierros de mayores de un número suficientemente elevado de entidades de población permite localizar temporalmente las «crisis de mortalidad» y hallar valores de su «intensidad relativa». Sin embargo, dado que no se puede aceptar la hipótesis de que, a largo plazo, la Tasa Bruta de Mortalidad de Mayores (TBMM) se mantuviera constante, estos datos «no pueden servir de base» para cálculos cuantitativos de la evolución temporal de la población en que se produjeron y, por ello, de los efectos de las crisis. No es fácil encontrar un valor para la «mortalidad basal» sobre la que calcular el exceso de mortalidad producido por una determinada crisis, cosa que posibilitaría hallar valores de estos efectos.

Un trabajo previo con los datos de números anuales de bautismos y de entierros de mayores parece que nos lleva a la conclusión de que, para «crisis de mortalidad de poca entidad», los datos de bautismos «pueden ser más eficientes que los de entierros» en la determinación de los efectos de las mismas, pues son, a nuestro entender, más adecuados para "proporcionar valores cuantitativos de los incrementos, o descensos, de bautismos (población)» generados por la crisis, o crisis sucesivas, dado que se puede aceptar la hipótesis de que la Tasa Bruta de Natalidad se mantuvo constante a lo largo de periodos dilatados de tiempo y, en nuestro caso, a lo largo del siglo XVIII.

Los «datos de números anuales de bautismos» se adaptan mejor que los de entierros a las exigencias estadísticas de una distribución lo más normal posible $y$, en este sentido, el método de tratamiento de los mismos que hemos desarrollado y aplicado para obtener la «mejor representación de su evolución temporal», basado en una comparación de cohortes sucesivas de números anuales de bautismos, parece que conduce a «representaciones lo suficientemente fidedignas» dentro de la precisión exigida al análisis. Con él hemos podido determinar los «periodos entre crisis» en los que la población, disminuida o no, estaba enjugando, o aumentando, sus pérdidas. La extensión temporal de estos periodos, por otra parte, permite un cierto tipo de medida de la intensidad de la crisis previa, a la vez que permite reconocer más fácilmente las «crisis menores» y su acumulación, si la hay, en el tiempo. Todo el trabajo realizado en este sentido está lejos de estar terminado, ya que pretendemos continuar ensayando el método desarrollado, en otras épocas de Asturias y en otros escenarios, a fin de «cono- 
cer mejor su aplicabilidad generalizada» a situaciones y poblaciones lo más variadas posible.

En relación con su aplicación particular al caso de la población rural de Asturias, hemos encontrado que en el siglo XVIII el Principado fue un ejemplo paradigmático de «la influencia de la disminución de la mortalidad en el crecimiento poblacional», ya que sólo sufrió dos crisis de mortalidad de cierta entidad, las de 1710-1711 y de17701771. Del año 1701 al 1800 , los bautismos, y por lo tanto la población, de la Asturias Rural, creció un 56,76 por ciento, lo que se llevó a cabo mediante un crecimiento sostenido promedio, del 4,55 por mil anual. Este crecimiento se produce, prácticamente, entre los años 1725 y 1769 (el 82,36 por ciento del crecimiento total durante el siglo, debido a un crecimiento anual sostenido del 7,58 por mil).

En todo este debate no hemos considerado el papel de las ciudades, de hecho de la única ciudad que hemos estudiado, Oviedo ${ }^{53}$, conocemos que en los años que fueron de 1701 a 1800 , Oviedo crece sólo un 25,13 por ciento, del cual es responsable un crecimiento anual sostenido del 2,27 por mil. Este comportamiento de Oviedo es el esperado, pero como esta ciudad era únicamente una de las seis entidades de población de más de 2500 habitantes (Boal, Pianton, Gijón, Nava, Oviedo y Luarca) que, en conjunto, albergaban 22605 habitantes, tendremos que llevar a cabo una investigación más extensa, englobando las otras cinco, a fin de establecer si el comportamiento de Oviedo-ciudad era generalizable a las demás «ciudades». La cifra de 2500 habitantes como límite inferior que caracteriza el carácter ciudadano de un colectivo poblacional, procede de mi trabajo sobre este aspecto de la cuestión titulado «Búsqueda de criterios para establecer el carácter ciudadano de las poblaciones del Reino de Aragón durante el Antiguo Régimen» ${ }^{54}$.

Para terminar, podríamos también concluir que el número de entidades de población cuyos datos de números anuales de bautismos, y de entierros, que se pretenden acumular para obtener la «representación lo más fidedigna posible de un colectivo total», no puede ser cualquiera, sino que su determinación requiere un estudio previo, estudio que no es baladí. Además, este número depende de muchas variables, entre las que hay que contar la distribución geográfica de las entidades de población dentro del territorio que van a representar, a fin de que, dentro de él, su distribución sea lo más aleatoria posible.

53. ANSÓN CALvo, M. C., «La Población Asturiana en el Siglo XVIII..., pp. 73-78.

54. Ansón CALvo, M. C., «Búsqueda de criterios para establecer el carácter ciudadano de las ....». Op. cit. Barcelona, 2003, pp. $145-170$. 